\title{
Delayed Transplantation of Adult Neural Precursor Cells Promotes Remyelination and Functional Neurological Recovery after Spinal Cord Injury
}

\author{
Soheila Karimi-Abdolrezaee, ${ }^{1}$ Eftekhar Eftekharpour, ${ }^{1}$ Jian Wang, ${ }^{1}$ Cindi M. Morshead, ${ }^{2,3}$ and Michael G. Fehlings ${ }^{1,2,3,4}$ \\ ${ }^{1}$ Division of Cell and Molecular Biology, Toronto Western Research Institute, Krembil Neuroscience Center, Toronto, Ontario, Canada M5T 2S8, and \\ ${ }^{2}$ Department of Surgery, ${ }^{3}$ Institute of Medical Sciences, and ${ }^{4}$ Division of Neurosurgery, University of Toronto, Ontario, Canada M5S 1A8
}

\begin{abstract}
Spinal cord injury (SCI) results in loss of oligodendrocytes demyelination of surviving axons and severe functional impairment. Spontaneous remyelination is limited. Thus, cell replacement therapy is an attractive approach for myelin repair. In this study, we transplanted adult brain-derived neural precursor cells (NPCs) isolated from yellow fluorescent protein-expressing transgenic mice into the injured spinal cord of adult rats at 2 and 8 weeks after injury, which represents the subacute and chronic phases of SCI. A combination of growth factors, the anti-inflammatory drug minocycline, and cyclosporine A immunosuppression was used to enhance the survival of transplanted adult NPCs. Our results show the presence of a substantial number of surviving NPCs in the injured spinal cord up to 10 weeks after transplantation at the subacute stage of SCI. In contrast, cell survival was poor after transplantation into chronic lesions. After subacute transplantation, grafted cells migrated $>5 \mathrm{~mm}$ rostrally and caudally. The surviving NPCs integrated principally along whitematter tracts and displayed close contact with the host axons and glial cells. Approximately $50 \%$ of grafted cells formed either oligodendroglial precursor cells or mature oligodendrocytes. NPC-derived oligodendrocytes expressed myelin basic protein and ensheathed the axons. We also observed that injured rats receiving NPC transplants had improved functional recovery as assessed by the Basso, Beattie, and Bresnahan Locomotor Rating Scale and grid-walk and footprint analyses. Our data provide strong evidence in support of the feasibility of adult NPCs for cell-based remyelination after SCI.
\end{abstract}

Key words: adult neural precursor cells; spinal cord injury; oligodendrocytes; remyelination; neurological recovery; rat

\section{Introduction}

Post-traumatic degeneration of spinal cord white matter contributes substantially to the pathophysiology of spinal cord injury (SCI). Even after severe contusive SCI, surviving axons persist in the subpial rim of white matter but exhibit demyelination, which occurs secondary to oligodendroglial cell death, and limited myelin gene expression as well as limited oligodendrocyte renewal after SCI (Li et al., 1996; Crowe et al., 1997; Casha et al., 2001). Previous studies from our group and others have shown that these injured surviving axons show dysfunctional conduction properties (Blight, 1983; Fehlings and Nashmi, 1996; Nashmi et al., 2000; Nashmi and Fehlings, 2001) mainly because of the associated changes in axonal potassium channel expression and distribution (Nashmi et al., 2000; Karimi-Abdolrezaee et al., 2004).

Received 0ct. 1, 2005; revised Jan. 3, 2006; accepted Feb. 15, 2006.

This work was supported by operating grants from the Canadian Institutes of Health Research (CIHR) to M.G.F. (CIHR-MT14459) and the Stem Cell Network to C.M.M. M.G.F. holds the Krembil Chair in Neural Repair and Regeneration. S.K.-A. was supported by fellowships from the CIHR and Ontario Neurotrauma Foundation. E.E. was supported by a fellowship grant from the Christopher Reeve Paralysis and Sam Schmidt Paralysis Foundations. We thank Vincent Cheng for technical assistance.

Correspondence should be addressed to Dr. Michael G. Fehlings, Krembil Chair in Neural Repair and Regeneration Division of Neurosurgery, University of Toronto, Toronto Western Hospital, University Health Network, Room 4W449, 399 Bathurst Street, Toronto, Ontario, Canada M5T 2S8. E-mail: michael.fehlings@uhn.on.ca.

DOI:10.1523/JNEUROSCI.4184-05.2006

Copyright $\odot 2006$ Society for Neuroscience $\quad 0270-6474 / 06 / 263377-13 \$ 15.00 / 0$
Unfortunately, despite the presence of endogenous neural stem cell populations within the adult spinal cord, the extent of oligodendrocyte differentiation from these endogenous precursor cells, even after infusion of exogenous growth factors (Kojima and Tator, 2002; Martens et al., 2002), is not sufficient to promote remyelination after SCI. Thus, restoration of the oligodendrocyte population by cell replacement therapy has been considered as a potentially attractive strategy to promote remyelination after SCI or disorders characterized by loss or a deficiency of myelin.

The existence of adult CNS multipotent neural stem cells (Reynolds and Weiss, 1992; Weiss et al., 1996a,b) has opened a new avenue for the growing field of cell therapy as a means to repair CNS injuries. Similar to embryonic stem cells (ESCs), adult neural precursor cells (NPCs) have shown an extensive capacity for self-renewal and multipotency in vitro (Reynolds and Weiss, 1992; Richards et al., 1992), and, importantly, they obviate the potential ethical issues surrounding the use of ESCs for regenerative therapies. The population of NPCs residing in the forebrain and spinal cord is maintained for life and can be considered as a potential source of transplantable cells for individuals with SCI or other myelin disorders. Single adult neural stem cells can be isolated in vitro in the presence of growth factors that enable the proliferation and formation of clonally derived colonies of cells. These free-floating colonies (called neurospheres) comprised $<1 \%$ neural stem cells (Morshead et al., 2002) and 
$>99 \%$ progenitor cells. Here, we define neural stem and their progeny, progenitor cells, as NPCs. The ability of brain-derived adult NPCs to subserve SCI repair has not been fully characterized.

In this study, we have explored the potential efficacy of adult NPCs transplanted into the spinal cord to promote remyelination and functional recovery after compressive SCI in rats. We have combined adult NPC transplantation with minocycline treatment and growth factor [platelet-derived growth factor (PDGF-AA), basic fibroblast growth factor (bFGF), and epidermal growth factor (EGF)] delivery to promote cell survival in the environment of the adult injured spinal cord to optimize the approach. Our results indicate that adult NPCs have the ability to survive, integrate with injured spinal cord tissue, generate mature oligodendrocytes, remyelinate the injured axons, and promote functional recovery after SCI.

\section{Materials and Methods \\ Animal care}

A total of 97 adult female Wistar rats (250 g; Charles River Laboratories, Wilmington, MA) were used in this study. All experimental protocols in this study were approved by the animal care committee of the University Health Network in accordance with the policies established in the Guide to the Care and Use of Experimental Animals prepared by the Canadian Council of Animal Care.

\section{Isolation and culturing of adult neural stem cells}

Adult neural stem cells were isolated from yellow fluorescent protein (YFP)-expressing transgenic mice [strain 129-Tg(ACTB-EYFP)2Nagy/J; The Jackson Laboratory, Bar Harbor, ME] as described previously (Tropepe Sibilia et al., 1999). Briefly, mice were killed by cervical dislocation, and the brains were excised under sterile conditions and transferred to artificial CSF (aCSF) solution containing $2 \mathrm{M} \mathrm{NaCl}, 1 \mathrm{M} \mathrm{KCl}, 1 \mathrm{M}$ $\mathrm{MgCl}_{2}, 155 \mathrm{~mm} \mathrm{NaHCO}, 108 \mathrm{~mm} \mathrm{CaCl}_{2}, 1 \mathrm{~m}$ glucose, and 1\% penicillin/ streptomycin (Sigma, St. Louis, MO). The subventricular zone of forebrain was dissected and transferred to a low-calcium aCSF solution (10 $\mathrm{ml}$ ) containing $40 \mathrm{mg}$ of trypsin, $20 \mathrm{mg}$ of hyaluronidase, and $4 \mathrm{mg}$ of kynurenic acid for $30 \mathrm{~min}$ at $37^{\circ} \mathrm{C}$. Then, trypsin was inactivated, and the tissue was mechanically dissociated into a cell suspension with a firepolished Pasteur pipette. Cells were plated on uncoated tissue culture flasks in serum-free medium $(200 \mathrm{ml})$ containing $20 \mathrm{ml}$ of DMEM/F-12, $4 \mathrm{ml}$ of $30 \%$ glucose, $3 \mathrm{ml}$ of $7.5 \% \mathrm{NaHCO}_{3}, 1 \mathrm{ml}$ of 1 м HEPES, $200 \mathrm{mg}$ of transferrin, $50 \mathrm{mg}$ of insulin, $19.25 \mathrm{mg}$ of putrescine, $20 \mu \mathrm{l}$ of selenium, $20 \mu \mathrm{l}$ of progestron, $1 \mu \mathrm{g}$ of FGF2, $2 \mu \mathrm{g}$ of EGF, and 1\% penicillin/ streptomycin for $7 \mathrm{~d}$. The neurospheres generated were passaged weekly by mechanical dissociation in the same medium (as above).

\section{In vitro immunocytochemistry}

Neurospheres were dissociated into single cells and plated on Matrigelcoated multichamber glass slides ( 4000 cells per chamber). The cells were grown in a culture medium containing the neurosphere growth medium plus $1 \%$ fetal bovine serum (FBS), EGF, and bFGF (20 ng/ml) for $2 \mathrm{~d}$. To induce differentiation, the medium was replaced with one in which the growth factors were withdrawn. Then, the cultures were grown for $7 \mathrm{~d}$, at which time they were fixed with $4 \%$ paraformaldehyde (PFA) and washed three times with PBS. The cultures were blocked with $1 \%$ bovine serum albumin (BSA), 5\% normal goat serum, and $0.3 \%$ Triton X-100 in $\mathrm{PBS}$ for $1 \mathrm{~h}$ at room temperature and exposed to the following primary antibodies: mouse anti-nestin (1:200; Chemicon, Temecula, CA) for undifferentiated cells, mouse anti-GFAP (1:100; Chemicon) for astrocytes, rabbit anti-PDGF- $\alpha$ receptor (PDGF- $\alpha$ R; 1:40; Santa Cruz Biotechnology, Santa Cruz, CA) for oligodendrocyte progenitor cells, mouse antiCNPase (1:100; Chemicon) for mature oligodendrocytes, and mouse anti-MAP-2a,b (1:200; Sigma) for neurons. The cultures were incubated with the primary antibody in PBS plus $1 \%$ BSA, $2 \%$ normal goat serum, and $0.3 \%$ Triton $\mathrm{X}-100$ for $2 \mathrm{~h}$ at room temperature. Cultures were washed three times with PBS and treated with fluorescent Alexa 594 goat anti-mouse secondary antibody (1:400; Molecular Probes, Eugene, OR) for $1 \mathrm{~h}$, washed three times with PBS, and coverslipped with Mowiol containing 4',6-diamidino-2-phenylindole (DAPI) to counterstain the nuclei. The images were taken using a Zeiss (Thornwood, NY) LSM 510 laser confocal microscope.

\section{Surgical procedures}

SCI. The aneurysm clip compression model of SCI used in our laboratory has been characterized extensively and described previously (Rivlin and Tator, 1978; Fehlings and Tator, 1992, 1995; Fehlings and Nashmi, 1995). Under inhalational anesthesia using halothane (1-2\%) and a 1:1 mixture of $\mathrm{O}_{2} / \mathrm{N}_{2} \mathrm{O}$, the surgical area was shaved and disinfected with $70 \%$ ethanol and betadine. A midline incision was made at the thoracic area (T4T9), and skin and superficial muscles were retracted. The rats underwent a T6-T8 laminectomy and received a $23 \mathrm{~g}$ clip (Walsh, Oakville, Ontario, Canada) compression injury for $1 \mathrm{~min}$ at the level of T7 of the spinal cord. The surgical wounds were sutured, and the animals were given postoperative analgesia and saline $(0.9 \% ; 5 \mathrm{ml})$ to prevent dehydration. Animals were allowed to recover and were housed in standard rat cages with absorbent bedding at a temperature of $27^{\circ} \mathrm{C}$. Their bladders were manually expressed three times daily until return of reflexive bladder control.

Transplantation of adult NPCs. Two weeks after injury, the animals were randomly divided into three groups: (1) plain injured group, which only received SCI; (2) injured control group, which received SCI, growth factors, minocycline, and cyclosporine A with no cell transplantation; and (3) injured NPC-transplanted group, which received SCI, growth factors, minocycline, cyclosporine A, and NPC transplantation. The injured rats were anesthetized using halothane inhalation (1-2\%) and a 1:1 mixture of $\mathrm{O}_{2} / \mathrm{N}_{2} \mathrm{O}$, and the spinal cord was reopened at the injury area. For NPC transplantation, the rats were injected with a cell suspension of adult NPCs. To prepare the cell suspension, neurospheres from passages 3-4 (P3-P4) were collected and mechanically dissociated into single cells. Cell viability was assessed by trypan blue. The cells were diluted in the growth medium $\left(50 \times 10^{3} / \mu \mathrm{l}\right)$ and used for cell transplantation. Using a Hamilton syringe connected to a microglass pipette [100 $\mu \mathrm{m}$ outer diameter (O.D.)], a total volume of $8 \mu$ l of cell suspension, containing 3-4 $\times 10^{5}$ live cells, was injected into the dorsal spinal cord, next to the midline. Between two and four intraspinal injections were made at $2 \mathrm{~mm}$ rostrally and $2 \mathrm{~mm}$ caudally to the injury site. To enhance the survival of the transplanted cells, a mixture of growth factors including PDGF-AA ( $1 \mu \mathrm{g} / 100 \mu \mathrm{l}$; Sigma), bFGF ( $3 \mu \mathrm{g} / 100 \mu \mathrm{l}$; Sigma), and EGF ( 3 $\mu \mathrm{g} / 100 \mu \mathrm{l}$; Sigma $)$ in a solution containing aCSF, BSA $(100 \mu \mathrm{g} / \mathrm{ml})$, and gentamycine $(50 \mu \mathrm{g} / \mathrm{ml})$ was infused for $7 \mathrm{~d}$ using a catheter connected to an osmotic minipump (model 1007D, $0.5 \mu \mathrm{l} / \mathrm{h}$; Alzet, Cupertino, CA). The catheter ( $300 \mu \mathrm{m}$ O.D.) was implanted intrathecally at the area of transplantation. The animals received a daily subcutaneous injection of cyclosporine A (10 mg/kg, Sandimmune; Novartis, East Hanover, NJ) starting $3 \mathrm{~d}$ before transplantation and continuing until the end of the experiments. The rats also received a daily injection of minocycline (50 $\mathrm{mg} / \mathrm{kg}$; Sigma) intraperitoneally for $10 \mathrm{~d}$ starting $3 \mathrm{~d}$ before transplantation. The control animals also received the same number of injections to the spinal cord with only growth medium. All behavioral and neuroanatomical outcome assessments of the transplanted and control animals were performed in a blinded manner.

\section{Immunohistochemistry on tissue sections}

Animals were killed with an overdose of pentobarbital (Somnotol, 35 $\mathrm{mg}$ ) and perfused transcardially with $4 \%$ PFA in $0.1 \mathrm{~m} \mathrm{PBS,} \mathrm{pH} \mathrm{7.4.} \mathrm{The}$ spinal cords were subsequently postfixed in the perfusing solution plus $10 \%$ sucrose overnight at $4^{\circ} \mathrm{C}$. Then, the tissues were cryoprotected in $20 \%$ sucrose in PBS for $24-48 \mathrm{~h}$ at $4^{\circ} \mathrm{C}$. A $1.5 \mathrm{~cm}$ length of the spinal cord centered at the injury site was separated and embedded in tissueembedding medium (HistoPrep; Fisher Scientific, Pittsburgh, PA) on dry ice. Cryostat sections $(10 \mu \mathrm{m})$ were cut and mounted onto gelatinsubbed slides and stored at $-70^{\circ} \mathrm{C}$. For immunostaining, the frozen slides were air dried at room temperature for $10 \mathrm{~min}$ and washed with PBS for $10 \mathrm{~min}$. Then they were blocked with $1 \%$ BSA, 5\% nonfat milk, and $0.3 \%$ Triton X-100 in PBS for $1 \mathrm{~h}$ at room temperature, and the primary antibody was applied in the same blocking solution overnight at $4^{\circ} \mathrm{C}$. 
The following primary antibodies were used: mouse anti-nestin (1: 200; Chemicon) for NPCs, rabbit anti-PDGF- $\alpha$ R (1:40; Santa Cruz Biotechnology) for oligodendrocyte progenitor cells, mouse anti-GFAP (1: 100; Chemicon) for astrocytes, mouse anti-adenomatous polyposis coli (APC; 1: 40; Calbiochem, La Jolla, CA), mouse anti-myelin basic protein (MBP; 1:1000; Sternberger Monoclonal, Berkeley, CA) for mature oligodendrocytes, mouse anti-MAP-2a,b (1:200; Sigma), and mouse anti- $\beta$ tubulin III (1:500; Covance, Denver, PA) for neurons, rabbit anti-NF200 (1:500; Sigma) for axons, and anti-p75 (1:1000; Chemicon) for Schwann cells. The slides were washed in PBS three times and incubated with fluorescent Alexa 594 goat anti-mouse secondary antibody (1:400; Molecular Probes) for $1 \mathrm{~h}$. In double staining for MBP and NF200, the slides were treated with mouse anti-MBP antibody first and then incubated with Alexa 594 secondary antibody. For the second labeling, the slides were incubated with rabbit anti NF200 antibody and subsequently incubated with Alexa 647 secondary antibody (1:400; Molecular Probes). The slides were washed three times with PBS and coverslipped with Mowiol mounting medium containing DAPI to counterstain the nuclei. The images were taken using a Zeiss 510 laser confocal microscope.

Cell quantification on the spinal cord tissue of transplanted rats was performed in an unbiased stereological manner according to the principles described by Königsmark (1970). For quantification of cell survival ( $n=3$ rats), the total number of YFP-expressing/DAPI-positive cells was counted. Based on our microscopic examination, the size of the cell body (including nucleus) of a grafted YFP-NPC is between 10 and $20 \mu \mathrm{m}$. To avoid counting the same cell in more than one section, we counted every fifth section (50 $\mu \mathrm{m}$ apart). We only quantified the YFP cell bodies that contained a nucleus (identified with DAPI). To quantify the differentiation pattern of transplanted cells, we used confocal microscopy to count the number of YFP-positive cells that were double-labeled with a different cell marker. For quantitative immunostaining ( $n=3$ rats), we chose the spinal cord sections with the highest number of YFP-positive cells. For each cell marker, we immunostained two tissue sections per rat (at least $50 \mu \mathrm{m}$ apart). Then we counted the number of YFP/DAPI-positive cells that were double-labeled cells with the cell marker in 10 random fields per section. On average, 100-200 cells were counted per section.

\section{5-Bromo-2-deoxyuridine incorporation studies}

Rats received 10 injections of 5-bromo-2-deoxyuridine (BrdU; $50 \mathrm{mg} / \mathrm{kg}$, i.p.; three injections per day for $3 \mathrm{~d}$ ) and were killed $2 \mathrm{~h}$ after the last injection. The animals were perfused transcardially, and tissues were collected as described above. Then, the slides were processed for immunostaining against the BrdU antibody. The sections were washed with $\mathrm{PBS}$, incubated in $2 \mathrm{~N} \mathrm{HCl}$ and $1 \%$ Triton $\mathrm{X}-100$ for $15 \mathrm{~min}$ at room temperature, and washed with $0.1 \mathrm{M}$ sodium borate in PBS for $10 \mathrm{~min}$. The slides were blocked with $1 \%$ BSA, $5 \%$ nonfat milk, and $0.3 \%$ Triton $\mathrm{X}-100$ in PBS for $1 \mathrm{~h}$ at room temperature and incubated with a mouse anti-BrdU antibody (1:100; BD-immuno, Oxford, UK) in the same blocking solution for overnight at $4{ }^{\circ} \mathrm{C}$. The slides were treated with fluorescent Alexa 594 goat anti-mouse secondary antibody (1:400; Molecular Probes) as described above (see Immunohistochemistry on tissue sections). The images were taken using a Zeiss 510 laser confocal microscope.

\section{Assessment of myelination}

For assessment of myelination, the lengths of the spinal cords, $\sim 1.5-2$ $\mathrm{mm}$ caudal to the injury site, underwent postfixation in $4 \%$ PFA and osmification in $1 \%$ OsO4 and were embedded in Araldite502/Embed812 embedding media (Electron Microscopy Sciences, Ft. Washington, PA). Semithin sections $(0.5 \mu \mathrm{m})$ were cut from the rostral face, stained with Toluidine Blue, and viewed using a Zeiss Axioplan 2 Deconvolution microscope. Myelination was assessed by a histologist blinded to the experimental groups. Digital images were taken at $1000 \times$ magnification. Three image fields $(93 \times 75 \mu \mathrm{m})$ per animal were chosen in the lateral white-matter areas, where our NPC-transplanted cells were mostly distributed. Using a nonbiased linear sampling protocol established in our laboratory (Nashmi and Fehlings, 2001), we assessed the myelination ratio in the plain injured $(n=2)$, injured control $(n=3)$, and injured NPC-transplanted $(n=3)$ animals. In summary, a grid of 10 equally spaced vertical lines ( $8.57 \mu \mathrm{m}$ apart) was overlaid onto the image. Axons superimposed by these vertical lines were analyzed in our approach using ImageJ software (developed at the National Institutes of Health, Bethesda, MD). Care was taken to avoid Schwann cell-derived myelinated axons. We measured the axonal diameter (d) as the shortest distance across the center of axons, avoiding the myelin sheath thickness. The axonal diameter plus the total myelin sheath thickness on both sides was defined as fiber diameter (D). The myelin ratio (MR) was calculated using the D/d ratio. Therefore, a completely demyelinated fiber would have $\mathrm{aR}=1$, and in the myelinated fibers, the ratio would be $>1$.

\section{Immunoelectron microscopy}

The rats were perfused transcardially with $4 \%$ PFA and $0.15 \%$ glutaraldehyde in phosphate buffer (PB). The spinal cords were postfixed in $4 \%$ PFA in $0.1 \mathrm{M} \mathrm{PB}$ at $4^{\circ} \mathrm{C}$. The spinal cord tissue were embedded in $3 \%$ agar (agarose A, biotechnology grade; Rose Scientific, Edmonton, Alberta, Canada) for vibratome sectioning. Free-floating sections $(100 \mu \mathrm{m})$ of the spinal cord were processed for immunoperoxidase staining. The sections were washed in PBS three times and preincubated in $0.1 \% \mathrm{H}_{2} \mathrm{O}_{2}$ in PBS for $15 \mathrm{~min}$ to quench the endogenous peroxidase activity. Then, the sections were blocked in 5\% milk, $1 \%$ BSA, and $0.05 \%$ Triton X-100 in PBS for $3 \mathrm{~h}$ at room temperature and incubated in rabbit anti-green fluorescent protein (GFP) antibody (1:100; Chemicon) overnight at $4^{\circ} \mathrm{C}$. The sections were washed in PBS three times and incubated in anti-rabbit HRP secondary antibody (1:200) overnight at $4^{\circ} \mathrm{C}$. After washing in PBS, the sections were postfixed in $0.1 \%$ glutaraldehyde for $10 \mathrm{~min}$ at room temperature and washed in $0.1 \mathrm{M} \mathrm{PB}$ three times. The slides were incubated in $0.04 \% \mathrm{DAB}$ for $30 \mathrm{~min}$, followed by a second incubation with $0.04 \%$ DAB plus $0.005 \% \mathrm{H}_{2} \mathrm{O}_{2}$ for $15 \mathrm{~min}$. The sections were washed in $\mathrm{PB}$ for $15 \mathrm{~min}$, treated with $1 \%$ osmium tetroxide in $0.1 \mathrm{M} \mathrm{PB}$ overnight, dehydrated in graded ethanol solutions, and embedded in Araldite502/ Embed-812 embedding media (Electron Microscopy Sciences). Thin plastic sections were cut on an ultratome, counterstained with uranyl and lead citrate, and examined with a transmission electron microscope (Hitachi 7000; Hitachi, Tokyo, Japan). The negative control was performed by omitting the anti-GFP antibody.

\section{Footprint analysis}

Footprint analysis was modified from the method of de Medinaceli et al. (1982). The forelimbs and hindlimbs of the rats were dipped in red and green dyes (nontoxic), respectively. Then the animals were trained to walk on a paper-covered narrow runway $(1 \mathrm{~m}$ length and $7 \mathrm{~cm}$ width). This narrow runway ensured that the animals walked along a straight path. To prevent the rats from pausing while passing the track, a very bright box was placed at the beginning of the runway. We also placed a dark box with their food at the end of track to encourage them to finish the task as fast as possible. To perform the measurements, we excluded the first and the last $15 \mathrm{~cm}$ of the print to avoid analyzing the beginning and end of the limb movements. If the rats stopped in the middle of the track, the test was repeated. Rats that dragged their hindlimbs and lacked adequate weight support were excluded from these experiments. The angle of rotation was measured as the angle made by two lines connecting the third toe and the stride line at the center of the paw pad. For interlimb coordination, the distance between the center pads of the ipsilateral forelimb and hindlimb was measured. For analyses, at least six steps from each side per print were measured per animal per group ( $n=8$ control; $n=8$ transplanted).

\section{Grid-walking analysis}

We performed grid-walk analysis to assess the deficits in the descending motor functions in a manner complimentary to the footprint analysis ( $n=8$ control; $n=10$ transplanted). The rats were allowed to cross a $10-\mathrm{cm}$-wide and 1-m-long horizontal runway of wooden grids that were elevated $30 \mathrm{~cm}$ from the ground. To avoid habituation of animals to the fixed bar spacing, the bars were irregularly spaced $(1-4 \mathrm{~cm})$ at each trial. Animals were trained for three sessions before injury. For baseline, postinjury, and post-transplantation tests, each animal walked on the grid three times. The tests were recorded on digital videotape, and analyses were performed off-line in a blinded manner. For quantitative purposes, we counted the number of hindlimb falls that occurred within an iden- 
tified $75 \mathrm{~cm}$ length of the crossway. One recording was performed before injury to determine the baseline for each animal. After injury, because of the loss of weight support, recordings were started 2 weeks later when the injured rats began to show adequate weight support. Then the analyses were performed weekly after transplantation for 6 weeks. For each session, the average number of paw falls of each rat was taken from three trials. In the baseline measurements, no stepping errors were observed. The injured rats with dragging hindlimbs were excluded from the analysis.

\section{Basso, Beattie, and Bresnahan open-field} locomotion score

The Basso, Beattie, and Bresnahan (BBB) openfield locomotion score was performed using the BBB Locomotor Rating Scale (Basso et al., 1995). For examination, the rats were placed individually in an open field with a nonslippery surface. The 22-point $(0-21)$ BBB scale was used to assess hindlimb locomotor recovery including joint movements, stepping ability, coordination, and trunk stability. A score of 21 indicates unimpaired locomotion as observed in uninjured rats. The tests were performed by two examiners who were blinded to the animals' treatments. The duration of each session was 4 min per rat. Two BBB tests were performed at 1 and 2 weeks after injury, and after transplantation of neural stem cells, the rats were tested weekly for 6 weeks after transplantation.

\section{Statistics}

All data are reported as means \pm SEM. ANOVA or nonparametric Kruskal-Wallis ANOVA was used to analyze normally distributed data or non-continuous data, not meeting normality assumptions, respectively. Differences in footprint, grid walk, and BBB scores between group means at each post-transplantation time were identified using Student's $t$ tests and a significant level of $p<0.05$ (SigmaStat statistical package; SPSS, Chicago, IL).

\section{Results}

\section{Adult neural stem cell colonies} are multipotent

To confirm that our passaged neurospheres were multipotent, we studied the differentiation pattern of adult NPCs in vitro. Dissociated cells from passage $3 / 4$ neurosphere colonies were plated on Matrigel-coated multichamber glass slides in a serum-free growth medium containing EGF and bFGF for $2 \mathrm{~d}$. The majority of the cells showed bipolar morphology with small cell bodies and elongated thin processes (Fig. 1C) and were immunoreactive for nestin, a marker for neural stem/progenitor cells (Fig. 1C-E).

When growth factors were removed and replaced with $1 \%$ fetal calf serum for 1 week, the cultures revealed a heterogeneous population of differentiated cells. Astroglia (GFAP positive) constituted the main differentiated (60\%) progeny of adult NPCs in vitro (Fig. $2 D-F$ ). We also observed that $\sim 20 \%$ of the cells differentiated into mature oligodendrocytes as confirmed by
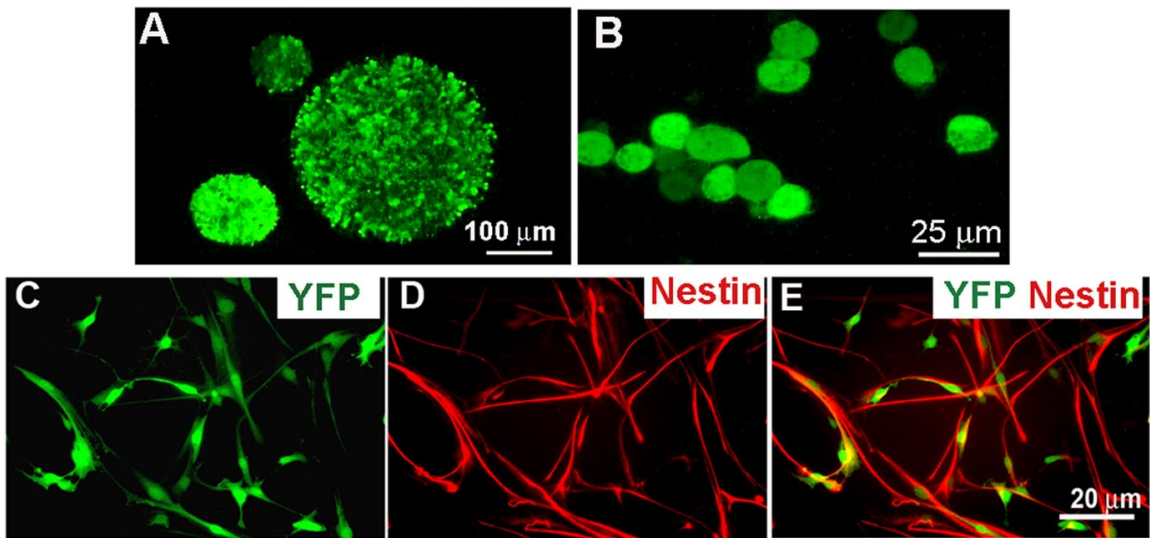

Figure 1. Isolated YFP-adult NPCs show nestin immunoreactivity in vitro. A, YFP-NPCs isolated from the subventricular zone of adult transgenic mice expressing YFP were grown as free-floating neurospheres in an uncoated tissue culture flask. The neurospheres were dissociated weekly into single cells and passaged for expansion. $\boldsymbol{B}$, Dissociated cells from passages 3-4 were transplanted into the injured spinal cord of rats. $\boldsymbol{C}-\boldsymbol{E}$, When the dissociated YFP cells were plated as a monolayer on Matrigelcoated multichamber glass slides, they acquired an elongated shape with long but unbranched processes. Immunocytochemistry on these cultures at $24-48 \mathrm{~h}$ after plating showed uniform expression of nestin in the majority of these cells.
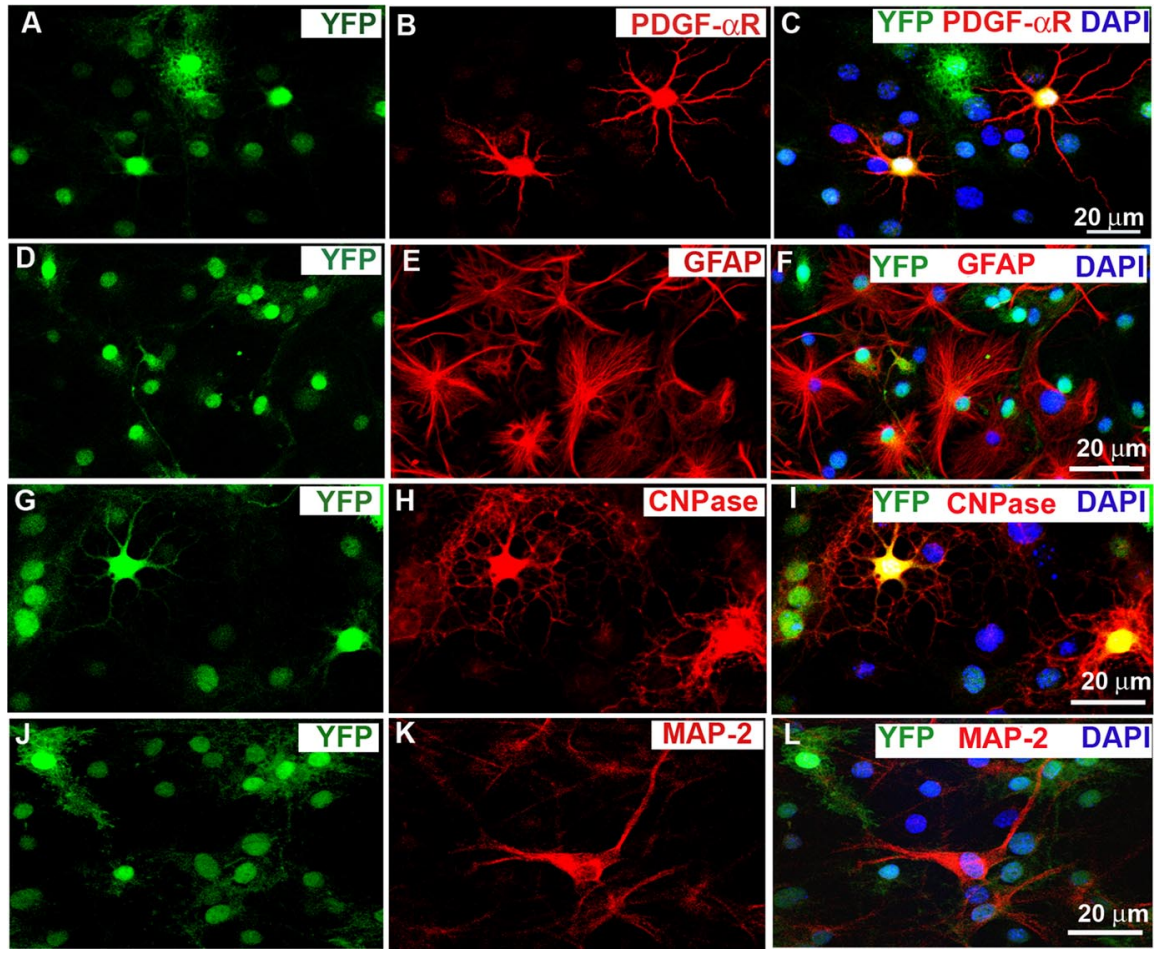

Figure 2. Differentiation pattern of adult YFP-NPCs in vitro. Dissociated YFP-NPCs were cultured as a monolayer on Matrigelcoated multichamber glass slides. For the first $2 \mathrm{~d}$, they were maintained in serum-free growth medium containing EGF and bFGF. On the third day, growth factors were withdrawn from the medium and replaced with $1 \% \mathrm{FBS}$. After $6 \mathrm{~d}$ in this condition, immunocytochemistry revealed a heterogeneous morphology of the YFP cells. A-C, A number of YFP cells (5\%) showed the antigenic properties of oligodendrocyte precursor cells (identified by PDGF- $\alpha$ R). $\boldsymbol{D}-\boldsymbol{F}$, The majority of the differentiated cells $(60 \%)$ showed immunoreactivity for GFAP and was considered as astrocytes. G-I, A population of YFP cells differentiated into mature oligodendrocytes (20\%, identified by CNPase). J-L, Among the cultured cells, a smaller number of the cells (10\%) were also positive for MAP-2, a marker for mature neurons.

CNPase immunoreactivity and morphological criteria (Fig. $2 G-$ $I)$. In addition to mature oligodendrocytes, we also found a smaller number of oligodendrocyte precursor cells (5\%) expressing PDGF- $\alpha$ R (Fig. $2 A-C$ ). A number of YFP cells (10\%) were MAP-2 positive, identifying differentiation into mature neurons (Fig. $2 J-L$ ). Among the differentiated cells, we also found a very small population of cells $(<1 \%)$ with the morphology of undif- 

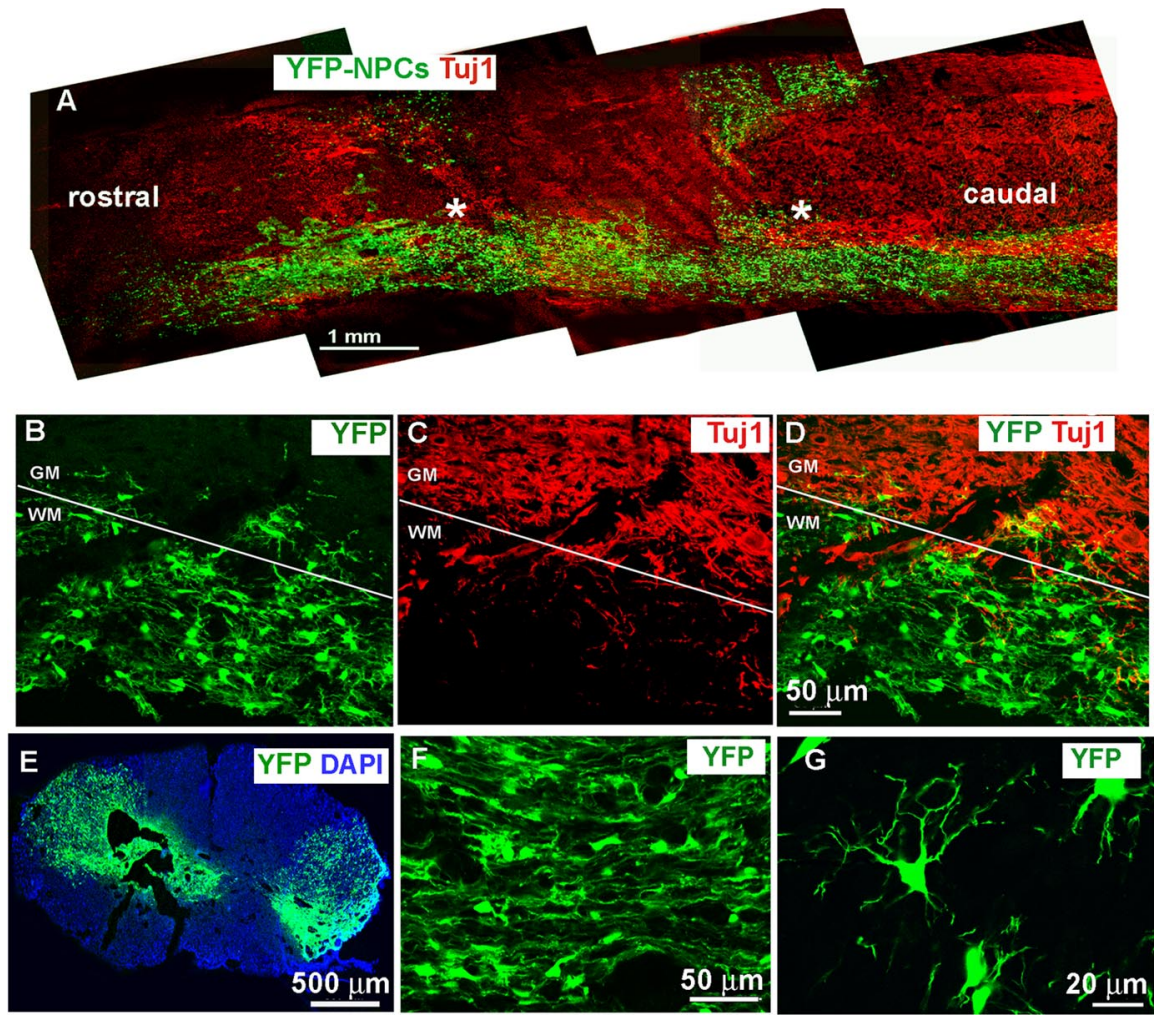

Figure 3. YFP-NPCs in the spinal cord of a subacutely injured rat 8 weeks after transplantation. $\boldsymbol{A}, \mathrm{A}$ confocal image from a longitudinal section of an injured spinal cord taken from the dorsal spinal cord of a transplanted rat above the central cavity. A low-magnified image shows the extent of YFP-NPC survival within the injured spinal cord 8 weeks after transplantation. Grafted YFP-NPCs (green) were dispersed along the rostrocaudal axis of the spinal cord $\sim 5 \mathrm{~mm}$ away from the implantation sites $\left(^{*}\right)$. YFP-NPCs also migrated to the contralateral site of the spinal cord to a lesser extent. Double labeling with the neuronal marker $\beta$ III tubulin (Tuj1) showed that YFP-NPCs reside predominantly in the white-matter area (A-D). Our histological data showed no signs of tumor formation in the spinal cord. $\boldsymbol{E}$, Confocal image of a transverse section of the spinal cord from a transplanted rat (8 weeks after transplantation) showing the distribution of YFP-NPCs in the lateral columns. $\boldsymbol{F}, \mathbf{G}$, YFP cells mainly showed multipolar morphology and extended numerous branches in the white-matter tissue along the length of axons. WM, White matter; GM, gray matter.

ferentiated cells that were positive for nestin immunoreactivity (data not shown), suggesting that even in the presence of differentiating factors, a small population of neurosphere-derived cells remains undifferentiated. Our results here confirm the previous observations that adult neural progenitor cells have the ability to differentiate into all three neural cell types in vitro (Reynolds and Weiss, 1992; Morshead et al., 1994; Weiss et al., 1996a,b; Martens et al., 2002).

\section{In vivo rat model of SCI}

We induced an in vivo model of compressive SCI at the midthoracic level (T6-T7) of the spinal cord using a modified aneurysm clip with a closing force of $23 \mathrm{~g}$ for $1 \mathrm{~min}$. The model characterization, histological assessment of injury, assessment of axonal integrity, molecular examination of axonal structure, and behavioral assessment have been characterized extensively by our group (Fehlings et al., 1989; Fehlings and Tator, 1995; Nashmi et al., 2000; Nashmi and Fehlings, 2001; Karimi-Abdolrezaee et al., 2004). This model of SCI in the rat accurately mimics the key features of human SCI. It creates a model of moderately severe SCI, which results in a central cavitation and loss of $80 \%$ of axons in the spinal cord white matter (Fehlings and Tator, 1995), demyelination of the surviving axons in the residual subpial rim with abnormally thin myelin sheaths as well as unmyelinated axons in the injured spinal cord and behavioral evidence of a spastic paraparesis (Nashmi et al., 1997; Nashmi and Fehlings, 2001). Collectively, the outcome of this model is of relevance to the majority of patients with chronic SCI.

Transplanted cells survive and migrate within the injured spinal cord

To examine the feasibility of adult NPC transplantation as a therapeutic tool for SCI, we transplanted brain-derived YFPNPCs into the injured spinal cord of rats at 2 and 8 weeks after SCI. These time points were chosen to model the subacute and chronic phases of SCI, respectively, which would represent the two most clinically relevant time points for therapeutic interventions.

We injected dissociated YFP-NPCs into the rostral and caudal areas to the injury site (1-2 mm away from the center of injury). Because of the central cavitation present at the epicenter of injury, we avoided cell injection at the injury site. To optimize the remyelination of injured axons in white matter, we attempted to inject the cells directly into the dorsal or lateral white matter.

Our preliminary transplantation experiments revealed a poor survival of adult YFP-NPCs within the injured spinal cord as early as 3 weeks after transplantation in a subacute SCI (supplemental Fig. 1, available at www.jneurosci.org as supplemental material). Hence, we modified our procedure to promote the survival of engrafted adult YFP-NSC, by infusing a mixture of growth factors including EGF, bFGF, and PDGF-AA into the spinal subarachnoid space using a catheter connected to an osmotic minipump for 1 week after transplantation. EGF and bFGF are potent growth factors that have been used to expand endogenous stem and progenitor populations within the subventricular zone both in vivo and in vitro (Reynolds and Weiss, 1992; Vescovi et al., 1993; Craig et al., 1996). PDGF-AA in combination with bFGF regulates the proliferative response of adult oligodendrocyte progenitors in vitro and in vivo (Lachapelle et al., 2002; Frost et al., 2003)

Indeed, the presence of the growth factor mixture for the first $7 \mathrm{~d}$ after transplantation resulted in a dramatic increase in the numbers of grafted cells within the injured cord (Fig. $3 A$ ). This finding suggests that the growth factor delivery enhanced the survival of engrafted adult YFP-NPCs or induced their proliferation over this $7 \mathrm{~d}$ period. To examine the proliferation of transplanted cells, animals received 10 injections of BrdU over a $3 \mathrm{~d}$ period before they were killed at 3 and 6 weeks after transplantation. At both times the animals were killed, we observed only a rare $\mathrm{YFP}+/ \mathrm{BrdU}+$ cell (Fig. 4), indicating that the increased numbers of YFP-expressing cells were likely the result of enhanced survival. We also did not observe any signs of tumorgenesis macroscopically or microscopically along the length of the transplanted spinal cords. To further optimize the survival of grafted adult YFP-NPCs in the injured spinal cord, we treated the rats with minocycline to inhibit the invasion of macrophages/ 
microglia into the injured cord and cyclosporin A to suppress the immune response to the transplanted donor cells that were derived from mice. Minocycline is a semisynthetic tetracycline that has antiinflammatory actions independent of its antibacterial effects. Previous studies have shown that minocycline is a multifunctional compound. It inhibits microglial activation after brain ischemia (Yrjanheikki et al., 1998, 1999) and SCI (Stirling et al., 2004). Minocycline displays neuroprotective properties by blocking cytochrome $c$ release (Zhu et al., 2002) and caspasedependent and -independent apoptosis (Wang et al., 2003) if it is administrated immediately after injury. In this study, cyclosporin A and minocycline treatment commenced $11 \mathrm{~d}$ after injury $(3 \mathrm{~d}$ before transplantation). Minocycline was continued daily for $7 \mathrm{~d}$ after transplantation, and cyclosporin A was delivered until the end of the experiments. All control animals (nontransplanted) also received growth factor, minocycline, and cyclosporin A treatment.

At 3 weeks $(n=5), 6$ weeks $(n=6), 8$ weeks $(n=8)$ and 10 weeks $(n=7)$ after transplantation, we performed immunohistochemical analyses to examine the survival, migration, proliferation, incorporation, and differentiation patterns of the grafted YFP-NPCs in the injured spinal cords. After the subacute transplantation, all transplanted rats showed a remarkable survival of YFP-NPCs in their spinal cords at all time points (Fig. $3 A$, data shown for 8 weeks). Quantitative analysis showed that at 8 weeks after transplantation, the average total number of YFP-positive cells $(110,204 \pm 61,911)$ present in the spinal cord was $36.74 \%$ of the original cell number $\left(3 \times 10^{5}\right)$ that had been injected into the spinal cord (Table 1).

The grafted YFP-NPCs were distributed along the rostrocaudal axis of the host spinal cord. At 8 weeks after transplantation, YFP-NPCs were observed at least $5 \mathrm{~mm}$ away from the implantation site in both the rostral and caudal directions (Fig. $3 A$ ). In regard to dorsoventral migration, we did not find the presence of YFP-NPCs in the ventral column when the injections were made in the dorsal or lateral column (Fig. $3 E$ ), suggesting that the rostrocaudal direction was the preferred rate of migration.

\section{NPCs differentiate into oligodendrocytes in the injured spinal cord}

After transplantation into the subacutely injured spinal cord, adult YFP-NPCs closely integrated into the injured spinal cord parenchyma. They mainly incorporated into white-matter tissue in the dorsal or lateral column (Fig. 3E). Morphologically, the YFP-grafted cells were generally distinguished by having a multipolar shape (Fig. $3 G$ ). These cells extended numerous projections along the host cellular profiles in the white matter, especially around the surviving oligodendrocytes and axons (see Figs. $6,7)$.

We examined the antigenic properties of YFP-NPCs in transplanted spinal cords using different neural cell markers. Before transplantation, the vast majority of NPCs are nestin positive (Fig. 1); however no immunoreactivity for nestin was observed among YFP-positive profiles at 2, 3, and 6 weeks after transplantation (Fig. $5 A-C$ ). This suggests that transplanted neural progenitor cells had started to differentiate in vivo.

Immunohistochemistry on tissue sections showed that transplanted cells differentiated into oligodendrocytes or astrocytes as identified by APC and GFAP immunoreactivity, respectively
Table 1. Quantification of cell survival in YFP-NSC-transplanted rats 8 weeks after transplantation

\begin{tabular}{lc}
\hline & Number of YFP/DAPI-positive cells \\
\hline Rat 1 & 111,912 \\
Rat 2 & 171,244 \\
Rat 3 & 47,456 \\
Mean \pm SD & $110,204 \pm 61,911$ \\
\hline
\end{tabular}

The total number of injected YFP-NSCs was 300,000 . The percentage of cell survival was $36.74 \%$. For quantification of cell survival $(n=3)$, the total number of YFP-expressing/DAPI-positive cells in the spinal cord was counted at 8 weeks after transplantation. We found that approximately $37 \%$ of YFP cells that were injected into the spinal cord survived after transplantation.

(Figs. 5, 6). Using confocal microscopy, we found that a large number of cells differentiated along an oligodendroglial lineage (Fig. 6). At 8 weeks after transplantation, $18.7 \pm 2.5 \%$ of the YFP-positive cells showed immunoreactivity for immature oligodendrocytes, $32.67 \pm 3.5 \%$ showed immunoreactivity for mature oligodendrocytes, and $5.6 \pm 2.08 \%$ showed immunoreactivity for GFAP-positive astrocytes (Fig. 6). These findings suggest that our transplantation strategies promote preferential survival and/or differentiation of adult neural progenitors toward an oligodendrocyte lineage. We did not observe any YFP-positive cells expressing $\beta$ III tubulin (Tuj1) or MAP-2 at 3, 6, 8, or 10 weeks after transplantation (Fig. 5G-I). This observation is in agreement with other studies showing the lack of neuronal differentiation by adult NPCs after transplantation into the injured spinal cord (Cao et al., 2001; Vroemen et al., 2003; Pfeifer et al., 2004) or dysmyelinated shiverer mouse cord (Windrem et al., 2004; our unpublished data). We also examined whether YFP-NPCs had the potential to differentiate into Schwann cells after transplantation into the injured spinal cord. Confocal immunohistochemistry revealed the lack of p75 immunoreactivity among grafted YFP cells (Fig. 5J-L). Our quantitative analysis revealed that $\sim 43 \pm 4.5 \%$ of YFP cells did not express any of the markers that we used.

Adult NPCs remyelinate the injured axons of the spinal cord We next examined the ability of newly generated oligodendrocytes to remyelinate the injured surviving axons of the spinal cord. Because YFP expression in the grafted adult NPCs was robust and expression was seen in the cell bodies and processes, we were able to examine the close proximity of donor processes with host axons. Using confocal immunohistochemistry on transplanted spinal cords, we found robust expression of MBP in the area occupied by YFP-positive cells (Fig. $7 A-C$ ) at $6-8$ weeks after transplantation. Indeed, YFP/MBP-positive cells were integrated within the host spinal cord in close association with the axons and endogenous oligodendrocytes. Confocal images of triple-labeled sections of the grafted spinal cord clearly displayed that YFP-positive processes had generated MBP around the NF200-immunopositive axons (Fig. 7). Figure 7 shows injured axons ensheathed by YFP/MBP-positive processes in both longi- 

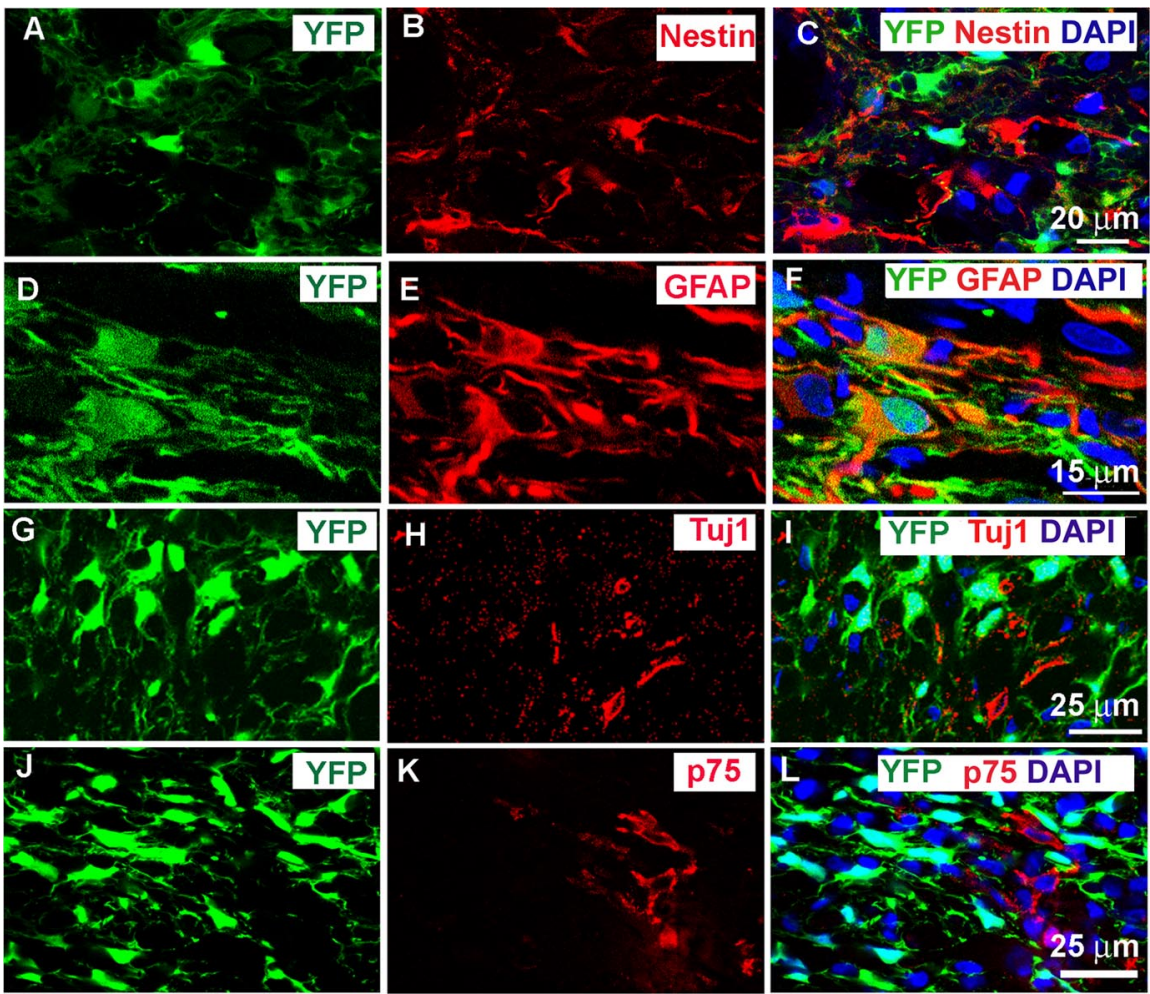

Figure 5. Differentiation of adult NPCs after transplantation. Confocal immunohistochemistry on longitudinal sections of the injured spinal cord of rats 6 weeks after transplantation is shown. $\boldsymbol{A}-\boldsymbol{C}, 0$ ur histological examination at 2, 3, and 6 weeks after transplantation showed the lack of nestin-positive YFP cells, suggesting that the grafted cells had already adopted a lineage fate. Although we were able to observe some nestin-positive cells among the host spinal cord cells, probably reactive astrocytes, YFP cells were nestin negative. $\boldsymbol{D}-\boldsymbol{F}$, Presence of some NPC-derived astrocytes identified by GFAP immunoreactivity. G-I, In contrast to our in vitro observations, no neuronal profiles (Tuj1 or MAP-2; data shown for Tuj1) were found among the YFP-positive cells after transplantation. $\boldsymbol{J}, \boldsymbol{K}$, Immunostaining with p75 indicated the lack of YFP-NPC-derived Schwann cells in the spinal cord. Although we observed the presence of some $\mathrm{p75}$-positive cells in both the transplanted and nontransplanted injured spinal cord, probably showing the invasion of endogenous Schwann cells into the cord, no coclocalization of p75 with YFP-derived cells was found.

tudinal (Fig. 7D-G) and cross (Fig. $7 H-K$ ) sections of the spinal cord. Figure $7 D-G$ clearly shows wrapping of one axon by a process colabeled with YFP and MBP that is seen emerging from a cell body of an NPC-derived oligodendrocyte. Colocalization of MBP and YFP labeling was also confirmed by deconvolution confocal microscopy (Fig. $7 P, Q$ ).

We further examined the remyelinating ability of engrafted adult NPCs, using electron microscopy on transplanted spinal cords at 6-8 weeks after transplantation. We observed remyelinated axons in white matter with thin myelin sheaths distributed among a few demyelinated and normally myelinated axons (Fig. 8 ). When we analyzed the myelination index among the plain injured, injured control, and injured NPC-transplanted groups, we found a significant increase in the MR in the NPCtransplanted group, indicating enhanced remyelination in this group compared with the plain and control injury groups (Fig. $8 D)(p \leq 0.001$; Kruskal-Wallis one-way ANOVA on ranks and Dunn's method post analysis). The myelin was significantly thicker in NPC-transplanted animals $(p \leq 0.001$; 0.544, 0.429, and $0.651 \mu \mathrm{m})$ compared with plain injured $(0.214,0.160$, and $0.258 \mu \mathrm{m})$ and control injured $(0.226,0.160$, and $0.295 \mu \mathrm{m}$; median: $25 \%$ and $75 \%$, respectively) animals. The enhanced myelination was apparent in all MR ranges, as shown in Fig. $8 E$ ( $p \leq$ 0.001; one-way ANOVA, followed by Tukey's post hoc analysis). For this analysis, the axonal measurements from three fields per animal was totaled, and the results were compared among averages for each experimental group $(n=2$ per plain injured group, $n=3$ per control injured group, and $n=3$ per NPC-transplanted group). These results suggest that functional improvement with NPC transplantation might reflect, at least in part, the enhanced remyelination seen.

To ensure that the remyelination was derived from transplanted cells, it was essential to visualize the grafted YFP cells by immunoelectron microscopy. To confirm the presence of surviving YFP-grafted cells in the spinal cord, the adjacent sections of grafted spinal cord tissues were also examined under fluorescence microcopy. All transplanted sections that were analyzed for immunoelectron microscopy exhibited a substantial number of surviving YFP cells in the spinal cord white matter, particularly in the lateral columns under fluorescence microscopic imaging. Our results showed clear evidence of YFP immunoreactivity on an ultrastrusctural level in the cytoplasm of cells in the injured spinal cord (Fig. $8 F_{I}-G_{I I}$ ). Electron micrographs of the transplanted area revealed peroxidase-reaction products in the cytoplasm and processes of myelinforming cells (Fig. 8G,$G_{I I}$ ). The YFP signal was also localized in myelin and cell membranes of the transplanted cells (Fig. $\left.8 H_{I}, H_{I I}\right)$.

\section{Behavioral studies}

To determine whether transplantation of adult NPCs improved recovery of function after SCI, we assessed the functional recovery using three independent behavioral tasks: BBB, footprint analysis, and gridwalk assessment. All neurobehavioral assessments were undertaken by observers blinded to the experimental groups. For the neurobehavioral assessment, the BBB test was performed to evaluate the hindlimb locomotor function in an open field (Fig. 9A). Immediately after SCI, all injured rats were paraplegic with no observable hindlimb movement. Injured rats continued to recover until 2 weeks after injury (before transplantation) and showed a mean BBB score of 8 , indicating planter placement of the paw with no weight support. At 2 weeks after transplantation (4 weeks after injury) (Fig. 9A), rats in all groups showed sufficient recovery to perform footprint and grid-walk analyses.

Animals with a BBB score of 10 show occasional weightsupported plantar stepping, which is crucial for grid-walk and footprint tests. Therefore, animals with a minimum BBB score of $\geq 10$ were further analyzed and included in the grid-walk and footprint analyses. Rats in the transplanted groups showed a significant improvement in the $\mathrm{BBB}$ scale relative to the plain injured and control groups (Fig. 9A). Although differences in the mean of BBB score in the transplanted group compared with the other groups were seen as early as 2 weeks after transplantation, it was statistically significant 3 weeks after transplantation and thereafter (Student's $t$ test; $p<0.05$ ). Our analysis showed that $85 \%$ of the cell-transplanted animals had a mean hindlimb score 
of $\geq 12$ at 5 and 6 weeks after transplantation, whereas in the plain injured and control groups, only 20 and $14 \%$ scored $>12$ at 6 weeks after transplantation, respectively. On average, the transplanted group had a mean BBB score of $12.3 \pm 0.33$ at 6 weeks after transplantation compared with the plain injured and control groups with mean scores of $11 \pm 0.35$ and $10.3 \pm$ 0.53 , respectively (Fig. $9 A)(p=0.017)$

Grid-walk analysis was performed to examine the deficits in descending fine motor control after SCI and transplantation (Metz et al., 2000, Merkler et al., 2001). To perform the grid-walk task, rats require forelimb-hindlimb coordination and voluntary motor movement integration. Rats were observed walking across a $1 \mathrm{~m}$ grid-way. During preinjury training, all rats accurately accomplished the test with no errors in foot placements. After SCI, the injured rats (all three groups: plain injured, control, and NPCtransplanted animals) demonstrated significant deficits in hindlimb placements and exhibited an average of 9-10 hindlimb footfall errors per session at 2 weeks after transplantation. The plain injured and control groups did not significantly improve over time; however, the rats transplanted with adult NPCs exhibited a progressive improvement in grid-walking performance. At 5 and 6 weeks after transplantation, the NPC-transplanted group exhibited significantly fewer footfalls $(6.3 \pm 1.02$ and $6.03 \pm 1.1$ at 5 and 6 weeks, respectively; $p<0.05$ ) (Fig. 9B) compared with the plain injured group $(9.83 \pm 2.2$ and $9.87 \pm 2.4$ at 5 and 6 weeks, respectively) and the control group (10.87 \pm 1.88 and $10.39 \pm 1.29$ at 5 and 6 weeks, respectively).

The footprint patterns of transplanted and control rats were analyzed for interlimb coordination and angle of rotation weekly after transplantation. The footprint patterns from uninjured rats showed a high degree of coordination of forelimb and hindlimb foot placements and a normal angle of rotation (Fig. 9C), whereas at 2 weeks after SCI, before transplantation, both of these parameters were significantly compromised in all injured animals. After transplantation, the transplanted group consistently demonstrated improvement in interlimb coordination such that, at 5 and 6 weeks after transplantation, interlimb coordination was significantly improved $(p<0.05)$ (Fig. 9D) $(1.87 \pm 0.133$ and $1.67 \pm 0.079 \mathrm{~cm}$ at 5 and 6 weeks, respectively) compared with the plain injured group $(2.25 \pm 0.28$ and $2.2 \pm 0.23 \mathrm{~cm}$ at 5 and 6 weeks, respectively) and the control group $(2.4 \pm 0.135$ and $2.11 \pm 0.187 \mathrm{~cm}$ at 5 and 6 weeks, respectively). The footprint assessments also revealed that the transplanted group had a consistent improvement in the angle of rotation in hindlimb placement in contrast to control animals that continued to display a markedly increased angle of rotation after SCI. At 6 weeks after transplantation, the transplanted group displayed a significant reduction $(p<0.05)$ (Fig. 9E) in hindlimb
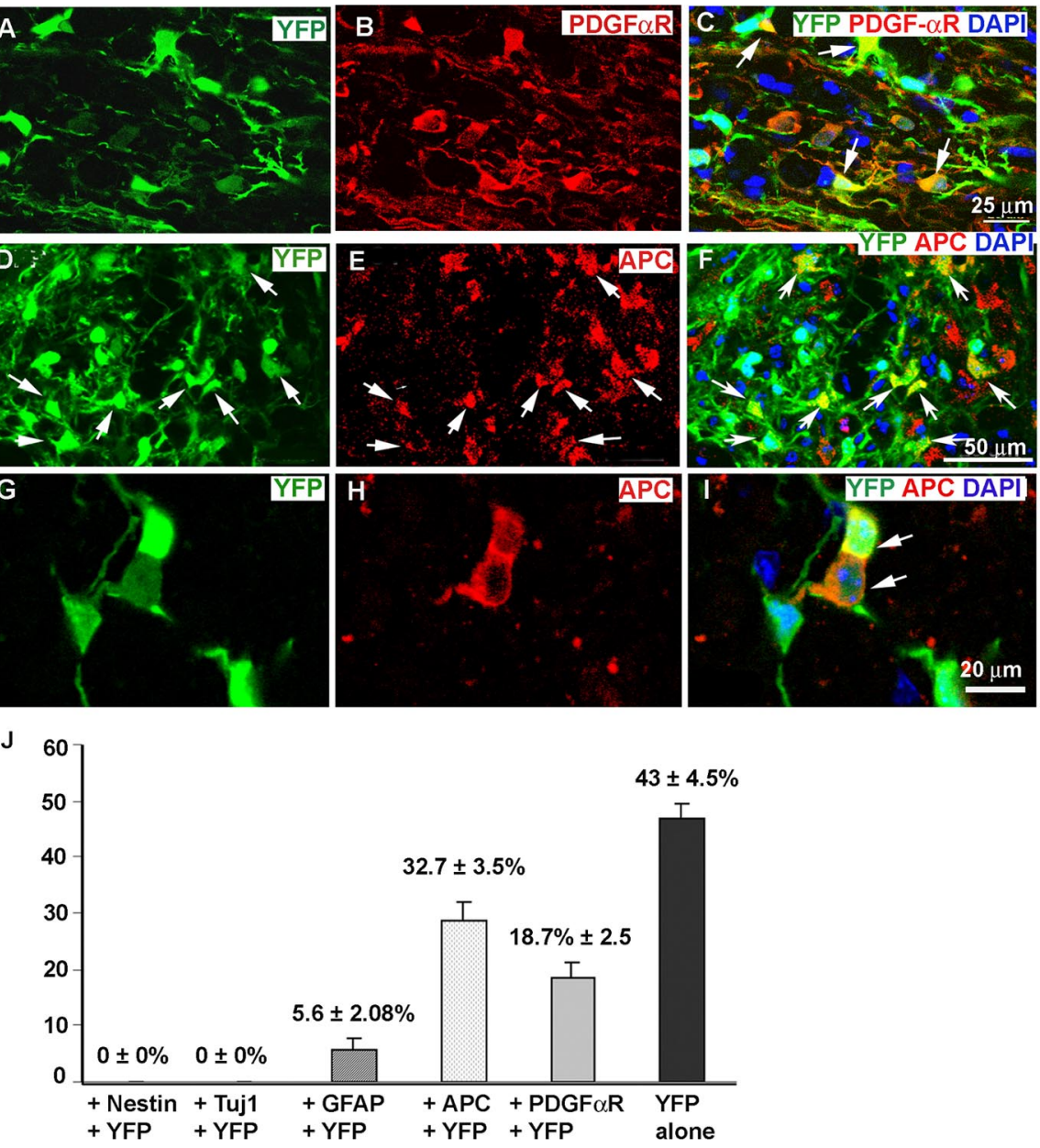

Figure 6. YFP-NPCs mainly differentiated along an oligodendrocyte lineage. Confocal immunohistochemistry on longitudinal sections of transplanted rats is shown. A-C, Grafted YFP-NPCs (green) displayed the antigenic properties of oligodendrocyte precursors (identified by PDGF- $\alpha$ R). $D$-I, Colocalization of YFP-positive cells with APC protein (a marker for mature oligodendrobserved among the YFP-positive cells. The grafted YFP cells also did not show any nestin immunoreactivity. Approximately $43 \pm$ $4.5 \%$ of YFP-positive cells did not show any colocalization with the cell markers that we used in this study. Error bars indicate SD.

angle of rotation $(12.07 \pm 1.1)$ compared with the plain injured group $(18.8 \pm 0.467)$ and the control group $(18.08 \pm 2.35)$.

Our results further indicate that the improved recovery of function in the transplanted group was exclusive to the beneficial effects of NPC transplantation, because there was no significant difference in the performance of the plain injured and control groups in all three behavioral tests that we used.

\section{Transplantation of adult NPCs in chronic SCI}

Although our therapeutic interventions demonstrated great success in optimizing the survival of engrafted adult NPCs in a subacute ( 2 weeks after SCI) model of SCI, it failed to exert similar effects after chronic ( 8 weeks after SCI) transplantation. We noticed the presence of surviving YFP-NPCs in a subset of our chronically transplanted injured rats, at 1 and 2 weeks after transplantation, which was contemporaneous with the availability of the exogenous infusion of the growth factor mixture, but not beyond that time point. At later time points, we only observed a large number of autofluorescent profiles in the injured spinal cord, which possibly reflected the presence of dead grafted cells 


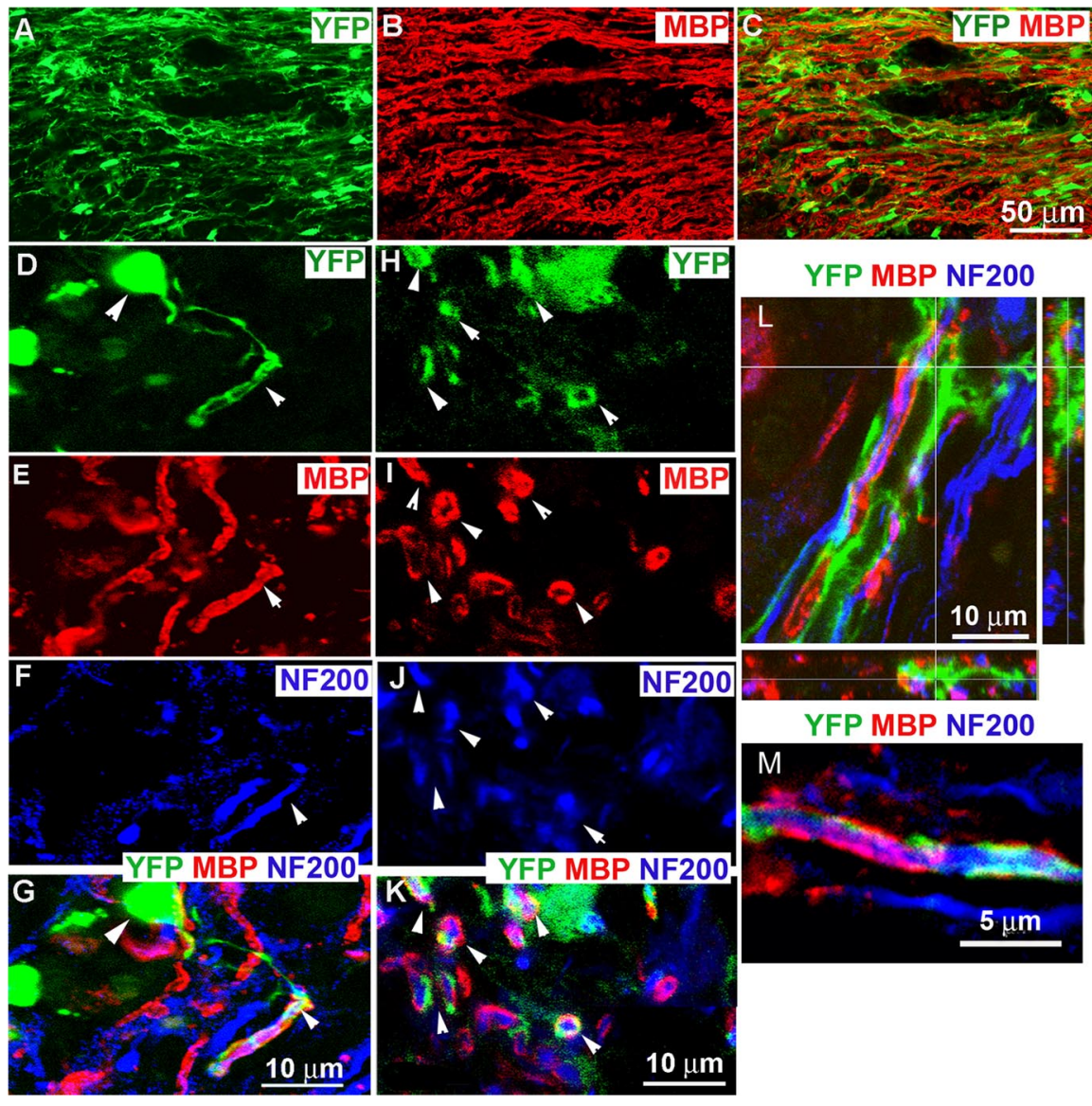

Figure 7. YFP-NPC-derived oligodendrocytes generate MBP and ensheath the injured axons of the spinal cord. $A-C$, Confocal images of longitudinal sections of an injured spinal cord 8 weeks after transplantation. The area grafted with YFP-NPCs (green) display a robust expression of MBP (red) in white matter of an injured spinal cord. Cell bodies of donor cells are surrounded with MBP. Triple-labeling experiments on longitudinal $(\boldsymbol{D}-\boldsymbol{G})$ and cross $(\boldsymbol{H}-\boldsymbol{K})$ sections of spinal cord white matter showed that MBP-expressing YFP-NPCs ensheathed the injured axons (identified by NF200; blue). These images ( $\boldsymbol{D}-\boldsymbol{G})$ clearly show the oligodendrocyte morphology of one grafted YFP cell (arrowheads) that extends its processes and expresses MBP around an injured axon and the close proximity of these cells with newly myelinated axons. $L, M$, Images taken by deconvolution confocal microscopy show a higher-magnification image confirming axonal ensheathment of MBP-expressing YFP-NPCs around the injured axons.

(supplemental Fig. 2, available at www.jneurosci.org as supplemental material). To rule out the possibility that the YFP signal of grafted NPCs may have been diminished in the chronically injured spinal cord, we immunostained a selection of transplanted spinal cord sections against an anti-GFP antibody that was able to detect YFP or GFP protein in vitro and in vivo. Our immunohistochemistry revealed the lack of YFP-positive cellular profiles in the rats that had been transplanted 6-8 weeks after SCI (data not shown). This evidence suggests that our current strategy is not sufficient for the repair of chronic SCI and that different approaches are needed to target the inhibitory barriers, which are present in the chronic spinal cord environment, that interfere with the survival and/or migration of transplanted adult NPCs.

\section{Discussion}

Our study provides strong evidence that transplantation of brainderived adult NPCs is an effective strategy to replace oligodendrocytes and promote the remyelination of surviving axons after SCI. Our results showing robust differentiation of myelinforming oligodendrocytes as well as improved functional neurological recovery strongly demonstrate the feasibility and efficacy of the adult source of NPCs as a potential therapeutic interven- tion for SCI and other diseases characterized by loss of or deficient myelin.

\section{Therapeutic interventions for promoting the cell survival} To optimize the survival of transplanted NPCs, we used several strategies. First, we locally infused a combination of growth factors to the transplanted area. We included the growth factors EGF, bFGF, and PDGF-AA, all of which have demonstrated beneficial effects on the proliferation and survival of NPCs in vitro and in vivo (Reynolds and Weiss, 1992; Weiss et al., 1996b; Lachapelle et al., 2002; Frost et al., 2003). EGF and bFGF are two potent mitogenic factors that have been used extensively in expanding NPCs isolated from the subventricular zone. Moreover, previous studies revealed that bFGF induced or enhanced the proliferation of neuronal precursor cells (Vescovi et al., 1993; Ray and Gage, 1994) as well as bipotent neuronal/glial precursors (Vescovi et al., 1993), indicating the advantages of this growth factor. PDGF-AA is another growth factor secreted by type 1 astrocytes in the CNS that promotes the proliferation of bipotential progenitors and O-2A cells, stimulates the differentiation of oligodendrocytes (Raff et al., 1988), and is also implicated in the survival of newly formed oligodendrocytes (Butt et al., 1997a,b). Moreover, PDGF, in synergy with bFGF, regulates the proliferative response of adult oligodendrocyte progenitors (Lachapelle et al., 2002; Frost et al., 2003). Our immunocytochemistry on the cultures of adult NPCs also showed the presence of a cell population expressing PDGF- $\alpha$ R, indicating the potential responsiveness of these progenitors among the grafted cells to PDGF-AA infusion in vivo (Fig. $2 A-C$ ).

Here, we combined PDGF-AA and bFGF in the growth factor infusate, to selectively increase the number of oligodendrocyte precursors after transplantation. Our results showing a very low proliferative activity of adult NPCs after transplantation into the spinal cord further support the potential of promoting factors to optimize the survival of engrafted cells. However, our behavioral assessments showed no additive beneficial effect of this shortterm infusion of growth factors on functional recovery, because our injured control animals that also received growth factors did not show significant neurological improvement compared with the plain injured animals that received no growth factors.

\section{Differentiation of adult NPCs}

We found that adult NPCs isolated from the subventricular zone of the forebrain are capable of generating all three neural cell types when they are cultured in a serum-based medium. These results confirm the multipotentality of these cells that had been extensively investigated previously (Reynolds and Weiss, 1992; Morshead et al., 1994).

After transplantation into the injured spinal cord, we found a 
clear preference for grafted cells to remain confined to the white matter and extend their projections along axons. We have made similar observations when these cells were transplanted into the CNS of dysmyelinated Shiverer mice (our unpublished data). Whether the cells are attracted by demyelinated/dysmyelinated axons and/or repelled by gray matter remains unclear.

When we characterized the fate of transplanted cells, we found no nestinexpressing cells, suggesting that they had acquired a more differentiated fate. We found a substantial number of donorderived oligodendrocytes in the injured spinal cord. Our quantitative analyses revealed the presence of both immature and mature myelin-forming oligodendrocytes among grafted cells. To distinguish these two different developmental stages of oligodendrocyte differentiation, we used PDGF- $\alpha \mathrm{R}$ as a marker for prooligodendrocytes (precursors) as well as APC and MBP markers for mature oligodendrocytes. Previous studies have shown that PDGF- $\alpha \mathrm{R}$ is only expressed on prooligodendrocytes and is subsequently lost before acquiring the signature myelin markers of mature oligodendrocytes (Butt et al., 1997a,b). By using these markers, we were ensured that we did not doubly count the same cells derived from an oligodendroglial lineage. We found that $\sim 50 \%$ of grafted cells differentiated along an oligodendroglial lineage (19\% oligodendrocyte precursors and 33\% mature oligodendrocytes). Of note, oligodendrocyte loss and demyelination are major secondary consequences of SCI. It is intriguing to speculate that the propensity of adult NPCs to form oligodendrocytes after transplantation into the adult injured spinal cord may reflect the influence of the host tissue to replenish a particular cell type to maximize repair.

No neuronal differentiation was found among grafted adult NPCs. We used two different neuronal markers, $\beta$ III tubulin and MAP-2, to identify both immature and mature neurons. Although we clearly observed the close association of YFPgrafted cells with endogenous neuronal processes using deconvolution confocal microscopy, we did not find any $\beta$ III tubulin and MAP-2 expression by the transplanted cells. These results are in agreement with previous studies showing the lack of neurogenesis by adult derived progenitor cells when they are transplanted in vivo (Cao et al., 2001; Vroemen et al., 2003; Pfeifer et al., 2004). As further support for this observation, there is evidence that the endogenous stem cell populations that reside in the forebrain and spinal cord differ in regard to their neuro-
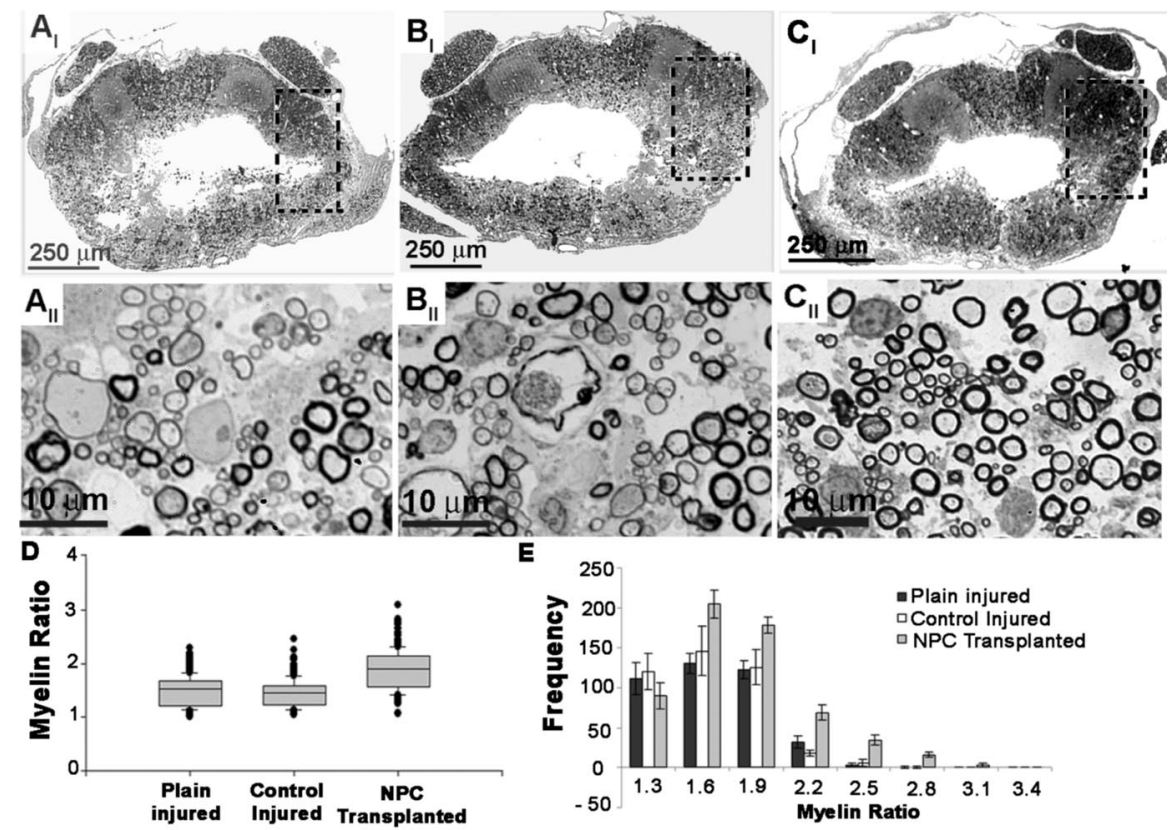

E 250
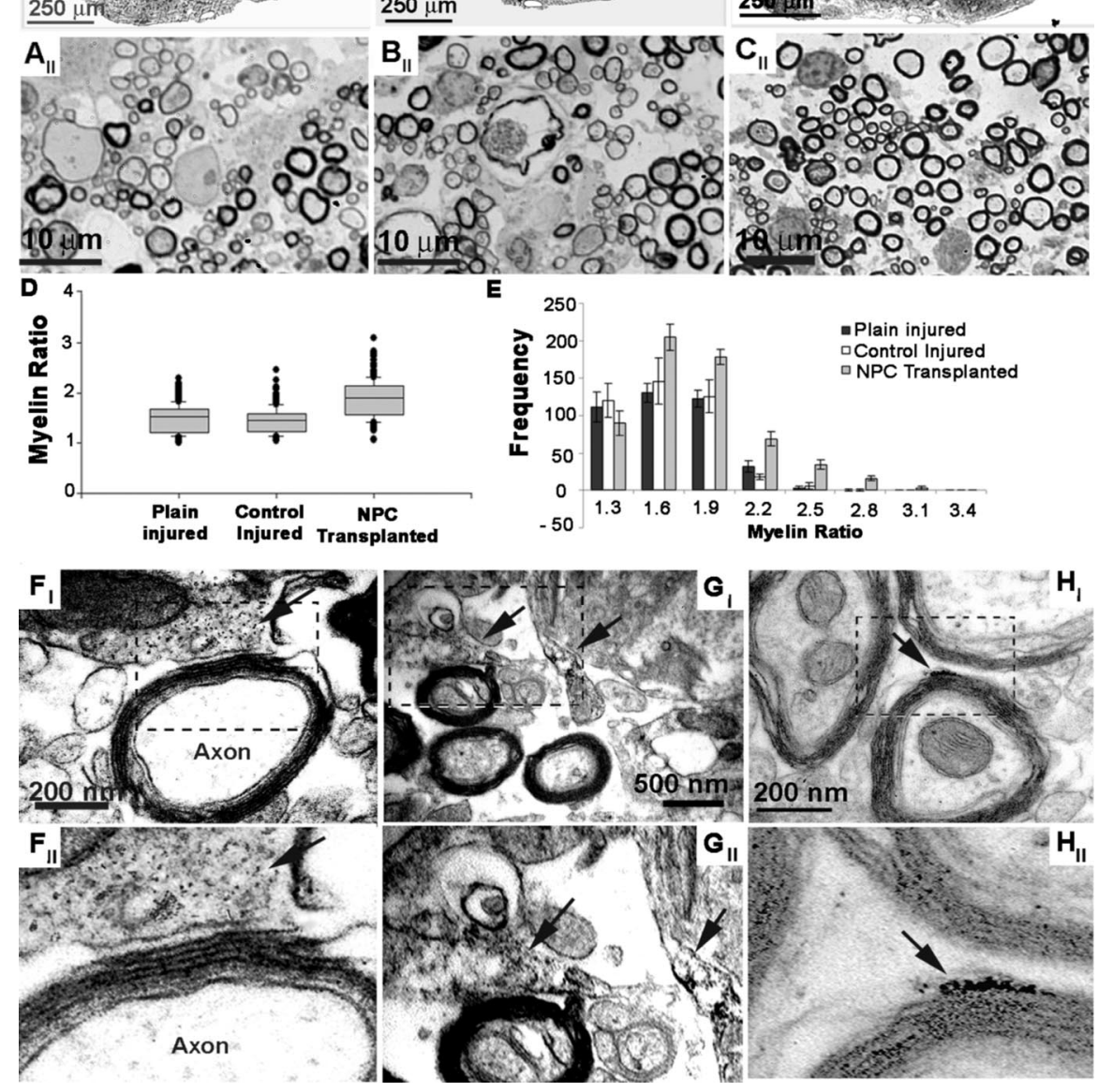

Figure 8. Evidence of remyelination of injured spinal cord white matter by grafted NPC 8 weeks after transplantation. $\boldsymbol{A}-\boldsymbol{C}$, Cross sections of osmium tetroxide-fixed semithin sections of the spinal cord stained with Toluidine Blue 8 weeks after transplantation are depicted for the plain injured, injured control, and NPC-transplanted groups, respectively, at low $\left(\boldsymbol{A}_{\boldsymbol{I}}-\boldsymbol{C}_{\boldsymbol{l}}\right)$ and higher $\left(\boldsymbol{A}_{\| I}-\boldsymbol{C}_{\boldsymbol{I}}\right)$ magnification. The enlargement of the microscopic fields in the boxed areas in $\boldsymbol{A}_{\boldsymbol{I}}-\boldsymbol{C}_{\text {I }}$ shows the examples of the myelin profiles present in spinal cord white matter of the plain injured, injured control, and NPC-transplanted groups, respectively. As observed in $\boldsymbol{C}_{I \prime}$, the NPC-transplanted group showed more extensive oligodendrocyte-myelinated profiles in the area that was occupied by YFP-NPCs. The presence of YFP-NPCs was confirmed by fluorescence microscopy in the adjacent sections. D, E, Myelin index measurements on the three groups showed a significant increase in the MR in the NPC-transplanted group, indicating enhanced myelination in this group compared with the plain and control injury groups ( $\boldsymbol{D} ; p<0.001$; Kruskal-Wallis one-way ANOVA on ranks and Dunn's method postanalysis). The myelin was significantly thicker in the NPC-transplanted animals ( $p<$ $0.001 ; 0.544,0.429$, and $0.651 \mu \mathrm{m})$ compared with the plain injured $(0.214,0.160$, and $0.258 \mu \mathrm{m})$ and control injured $(0.226$, 0.160 , and $0.295 \mu \mathrm{m}$ ) animals (median: 25 and $75 \%$, respectively). The enhanced myelination with NPC transplantation was further apparent by plotting the frequency distribution of MRs $(\boldsymbol{E} ; p<0.001$; one-way ANOVA, followed by Tukey's post hoc analysis). This plot ( $\boldsymbol{E})$ illustrates a rightward shift toward enhanced myelination with NPC transplantation. Error bars indicate SD. $\boldsymbol{F}_{\boldsymbol{l}} \boldsymbol{G}_{\boldsymbol{l}}$ Immunoelectron micrographs are depicted, which provide evidence for the spatial overlap of YFP expression and myelin formation around axons in the NPC-transplanted spinal cords. Labeling of the peroxidase reaction product was seen in the YFP cell cytoplasm ( $\boldsymbol{F}_{\boldsymbol{l}}$, arrows) as well as the processes ( $\boldsymbol{G}_{\boldsymbol{l}}$, arrows). $\boldsymbol{F}_{\boldsymbol{l}}, \boldsymbol{G}_{\boldsymbol{l}}$, Higher magnification of the boxed areas in $\boldsymbol{F}_{\boldsymbol{l}}$ and $\boldsymbol{G}_{\boldsymbol{I}}$ clearly shows the presence of peroxidase reaction product in the cytoplasm and cell processes of YFP cells. $\boldsymbol{H}_{\boldsymbol{l}}$, YFP-positive processes from myelinating donor-derived cells were seen in close association with an axon. $\boldsymbol{H}_{\boldsymbol{I}}$, Enlargement of the boxed

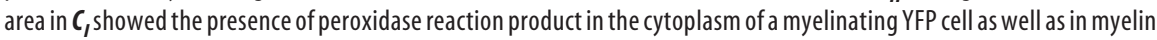
membrane around the axons.

genic capacities. Studies by van der Kooy's group (Martens et al., 2002) showed that in vivo infusion of growth factors induced generation of neurons from the endogenous NPCs around the lateral ventricles but not from the NPCs around the fourth ventricle or spinal cord canal. NPCs in the spinal cord were only 

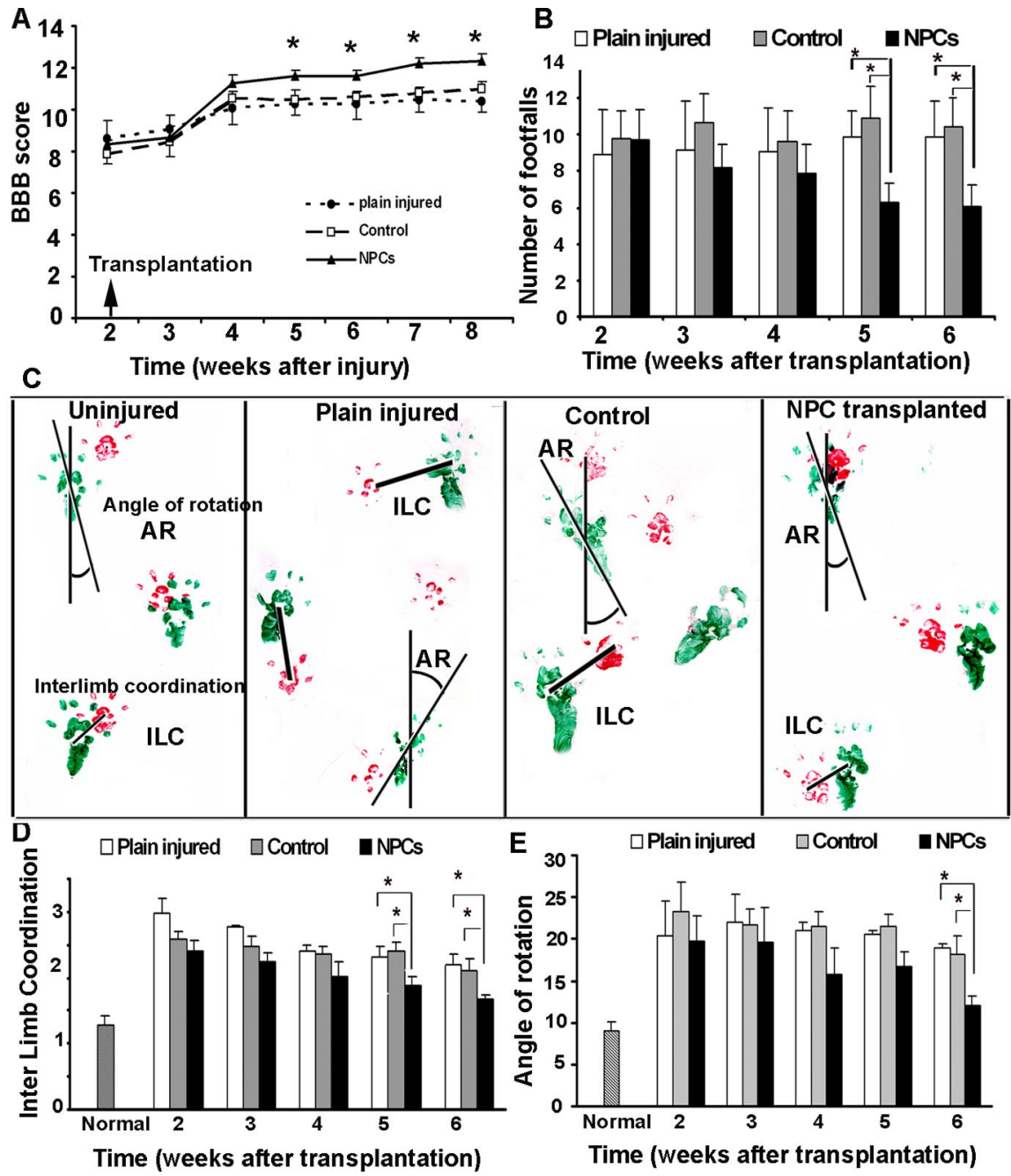

Figure 9. Subacute transplantation of YFP-NPCs resulted in a significant locomotor recovery compared with injured rats in the control group. $A, B B B$ rating scale showed a significant improvement in the locomotor BBB score in transplanted rats at 3 weeks after transplantation compared with the plain injured and control groups ( $n=5$ for plain injured group and $n=8$ for other groups). $\boldsymbol{B}$, Using grid-walk analysis, transplanted rats also showed fewer errors in hindlimb placements at 5 and 6 weeks after transplantation compared with the plain injured and control groups ( $n=5$ for plain injured group and $n=8$ for other groups). $\boldsymbol{C}$, Representative footprints of normal, plain injured, control, and grafted rats ( $n=5$ for plain injured group and $n=8$ for other groups) shows improvement in interlimb coordination as well as angle of rotation in the transplanted group compared with the plain injured and control groups. $\boldsymbol{D}, \boldsymbol{F}$, Footprint analysis revealed that transplantation with adult NPCs significantly improved interlimb coordination and reduced the hindlimb angle of rotation at 5 and 6 weeks after transplantation. The data show the mean \pm SEM. ${ }^{*} p<0.05$

capable of generating glial progeny. Considering this evidence, the endogenous environment of the spinal cord may lack promoting factors or contain inhibitory factors that make it an unfavorable environment for generating new neurons from adult NPCs. Together, our data indicate that if the adult NPCs are considered for neuronal replacement therapies, appropriate strategies are required to direct them toward a neuronal fate.

Our quantitative analysis also revealed that $\sim 40 \%$ of YFP cells did not express any of the markers that we used. Although we used laser confocal microscopy for quantification of differentiated donor-derived cells and applied extra caution in identifying YFP-derived astrocytes, we may have underestimated the number of YFP-GFAP-positive cells because of difficulty in GFAP quantification in vivo, given that GFAP is found in processes and therefore difficult to colocalize with YFP. Another explanation is that we may have underestimated the extent of oligodendroglial differentiation, because there is a broad range of cellular markers for oli- godendroglial progenies at different time points of their differentiation. With our observation that no nestin immunoreactivity was found in the YFP-donor cells, it is unlikely that the rest of the YFP cells remain undifferentiated after transplantation. Moreover, our immunohistochemical data ruled out the possibility of Schwann cell differentiation by adult NPCs.

\section{Transplantation of NPCs into chronically injured spinal cord}

Although our therapeutic interventions optimized the survival of engrafted adult NPCs in a subacute (2 weeks after SCI) model of SCI, they failed to exert similar effects after chronic ( 8 weeks after SCI) transplantation. It is possible that astrogliosis, which occurs during the chronic stage of injury and inhibits neuronal regeneration, may have a key role in the failure of cell survival and migration of grafted adult NPCs in this setting. The astroglial scar could thus inhibit migration and survival of grafted cells after chronic SCI. As a supportive observation, our microscopic examination of the chronically transplanted rats revealed the presence of clusters of dead cells in the vicinity of the implantation sites (supplemental Fig. 2, available at www.jneurosci.org as supplemental material), suggesting that the lack of cell migration and integration may have contributed to the poor cell survival after chronic SCI. Recent findings by Keirstead et al. (2005) also showed that even when transplanted cells from an hESC source survived after chronic SCI and differentiated into oligodendrocytes, they failed to remyelinate axons or promote functional recovery. These results suggest that, in addition to astrogliosis, there are other inhibitory factors that limit remyelination of axons after chronic SCI. Alternatively; this could also reflect the lack of appropriate trophic factors for remyelination after chronic SCI.

\section{Conclusions}

Our studies provide strong evidence that adult source of brainderived NPCs can be considered as a potential therapeutic strategy for the treatment of SCI. Although our transplantation strategies were successful in the subacute phase of SCI, we still need to overcome the inhibitory obstacles presented by chronic SCI that interfere with cell transplantation. Although the strategy of using adult NPCs for repair of CNS lesions in the clinical setting requires further development, this could, in concept, be accomplished by deriving these cells in one of several ways: (1) from the brain of the SCI patient (autograft) using stereotactic approaches, as supported by evidence for the presence of NPCs in human cerebral white matter (Nuns et al., 2003); (2) from the brains of human organ donors or from temporal lobectomy specimens derived during neurosurgical correction of refractory epi- 
lepsy (allograft); and (3) by the generation of human cell linederived NPCs.

\section{References}

Basso DM, Beattie MS, Bresnahan JC (1995) A sensitive and reliable locomotor rating scale for open field testing in rats. J Neurotrauma 12:1-21.

Blight AR (1983) Axonal physiology of chronic spinal cord injury in the cat: intracellular recording in vitro. Neuroscience 10:1471-1486.

Butt AM, Hornby MF, Kirvell S, Berry M (1997a) Platelet-derived growth factor delays oligodendrocyte differentiation and axonal myelination in vivo in the anterior medullary velum of the developing rat. J Neurosci Res 48:588-596.

Butt AM, Hornby MF, Ibrahim M, Kirvell S, Graham A, Berry M (1997b) PDGF-alpha receptor and myelin basic protein mRNAs are not coexpressed by oligodendrocytes in vivo: a double in situ hybridization study in the anterior medullary velum of the neonatal rat. Mol Cell Neurosci 8:311-322.

Cao QL, Zhang YP, Howard RM, Walters WM, Tsoulfas P, Whittemore SR (2001) Pluripotent stem cells engrafted into the normal or lesioned adult rat spinal cord are restricted to a glial lineage. Exp Neurol 167:48-58.

Casha S, Yu W, Fehlings M (2001) Oligodendrocyte apoptosis occurs along degenerating axons and is associated with FAS and p75 expression following spinal cord injury in the rat. Neuroscience 103:203-218.

Craig CG, Tropepe V, Morshead CM, Reynolds BA, Weiss S, van der Kooy D (1996) In vivo growth factor expansion of endogenous subependymal neural precursor cell populations in the adult mouse brain. J Neurosci 16:2649-2658.

Crowe M, Bresnahan J, Shuman S, Masters J, Beattie M (1997) Apoptosis and delayed degeneration after spinal cord injury in rats and monkeys. Nat Med 3:73-76.

de Medinaceli L, Freed WJ, Wyatt RJ (1982) An index of the functional condition of rat sciatic nerve based on measurements made from walking tracks. Exp Neurol 77:634-643.

Fehlings MG, Nashmi R (1995) Assessment of axonal dysfunction in an in vitro model of acute compressive injury to adult rat spinal cord axons. Brain Res 677:291-299.

Fehlings MG, Nashmi R (1996) Changes in pharmacological sensitivity of the spinal cord to potassium channel blockers following acute spinal cord injury. Brain Res 736:135-145.

Fehlings MG, Tator CH (1992) The effect of direct current field polarity on recovery after acute experimental spinal cord injury. Brain Res 579:32-42.

Fehlings MG, Tator CH (1995) The relationships among the severity of spinal cord injury, residual neurological function, axon counts, and counts of retrogradely labeled neurons after experimental spinal cord injury. Exp Neurol 132:220-228.

Fehlings MG, Tator CH, Linden RD (1989) The relationships among the severity of spinal cord injury, motor and somatosensory evoked potentials and spinal cord blood flow. Electroencephalogr Clin Neurophysiol 74:241-259.

Frost EE, Nielsen JA, Le TQ, Armstrong RC (2003) PDGF and FGF2 regulate oligodendrocyte progenitor responses to demyelination. J Neurobiol 54:457-472.

Karimi-Abdolrezaee S, Eftekharpour E, Fehlings MG (2004) Temporal and spatial patterns of Kv1.1 and Kv1.2 protein and gene expression in spinal cord white matter after acute and chronic spinal cord injury in rats: implications for axonal pathophysiology after neurotrauma. Eur J Neurosci 19:577-589.

Keirstead HS, Nistor G, Bernal G, Totoiu M, Cloutier F, Sharp K, Steward O (2005) Human embryonic stem cell-derived oligodendrocyte progenitor cell transplants remyelinate and restore locomotion after spinal cord injury. J Neurosci 25:4694-4705.

Kojima A, Tator CH (2002) Intrathecal administration of epidermal growth factor and fibroblast growth factor 2 promotes ependymal proliferation and functional recovery after spinal cord injury in adult rats. J Neurotrauma 19:223-238.

Königsmark BW (1970) Methods for counting of neurons. In: Contemporary research methods in neuroanatomy (Nauta WJH, Ebbesson SOE, eds), pp 315-340. New York: Springer.
Lachapelle F, Avellana-Adalid V, Nait-Oumesmar B, Baron-Van Evercooren A (2002) Fibroblast growth factor-2 (FGF-2) and platelet-derived growth factor $\mathrm{AB}$ (PDGF $\mathrm{AB}$ ) promote adult SVZ-derived oligodendrogenesis in vivo. Mol Cell Neurosci 20:390-403.

Li GL, Brodin G, Farooque M, Funa K, Holtz A, Wang WL, Olsson Y (1996) Apoptosis and expression of Bcl-2 after compression trauma to rat spinal cord. J Neuropathol Exp Neurol 55:280-289.

Martens DJ, Seaberg RM, van der Kooy D (2002) In vivo infusions of exogenous growth factors into the fourth ventricle of the adult mouse brain increase the proliferation of neural progenitors around the fourth ventricle and the central canal of the spinal cord. Eur J Neurosci 16:1045-1057.

Merkler D, Metz GA, Raineteau O, Dietz V, Schwab ME, Fouad K (2001) Locomotor recovery in spinal cord-injured rats treated with an antibody neutralizing the myelin-associated neurite growth inhibitor Nogo-A. J Neurosci 21:3665-3673.

Metz GA, Merkler D, Dietz V, Schwab ME, Fouad K (2000) Efficient testing of motor function in spinal cord injured rats. Brain Res 883:165-177.

Morshead CM, Reynolds BA, Craig CG, McBurney MW, Staines WA, Morassutti D, Weiss S, van der Kooy D (1994) Neural stem cells in the adult mammalian forebrain: a relatively quiescent subpopulation of subependymal cells. Neuron 13:1071-1082.

Morshead CM, Craig CG, van der Kooy D (1998) In vivo clonal analyses reveal the properties of endogenous neural stem cell proliferation in the adult mammalian forebrain. Development 125:2251-2261.

Nashmi R, Fehlings MG (2001) Changes in axonal physiology and morphology after chronic compressive injury of the rat thoracic spinal cord. Neuroscience 104:235-251.

Nashmi R, Imamura H, Tator CH, Fehlings MG (1997) Serial recording of somatosensory and myoelectric motor evoked potentials: role in assessing functional recovery after graded spinal cord injury in the rat. J Neurotrauma 14:151-159.

Nashmi R, Jones OT, Fehlings MG (2000) Abnormal axonal physiology is associated with altered expression and distribution of kv1.1 and $\mathrm{kv} 1.2 \mathrm{~K}^{+}$ channels after chronic spinal cord injury [In Process Citation]. Eur J Neurosci 12:491-506.

Nunes MC, Roy NS, Keyoung HM, Goodman RR, McKhann Jr G, Jiang L, Kang J, Nedergaard M, Goldman SA (2003) Identification and isolation of multipotential neural progenitor cells from the subcortical white matter of the adult human brain. Nat Med 9:439-447.

Pfeifer K, Vroemen M, Blesch A, Weidner N (2004) Adult neural progenitor cells provide a permissive guiding substrate for corticospinal axon growth following spinal cord injury. Eur J Neurosci 20:1695-1704.

Raff MC, Lillien LE, Richardson WD, Burne JF, Noble MD (1988) Plateletderived growth factor from astrocytes drives the clock that times oligodendrocyte development in culture. Nature 333:562-565.

Ray J, Gage FH (1994) Spinal cord neuroblasts proliferate in response to basic fibroblast growth factor. J Neurosci 14:3548-3564.

Reynolds BA, Weiss S (1992) Generation of neurons and astrocytes from isolated cells of the adult mammalian central nervous system. Science 255:1707-1710.

Richards LJ, Kilpatrick TJ, Bartlett PF (1992) De novo generation of neuronal cells from the adult mouse brain. Proc Natl Acad Sci USA 89:8591-8595.

Rivlin AS, Tator CH (1978) Effect of duration of acute spinal cord compression in a new acute cord injury model in the rat. Surg Neurol $10: 38-43$.

Stirling DP, Khodarahmi K, Liu J, McPhail LT, McBride CB, Steeves JD, Ramer MS, Tetzlaff W (2004) Minocycline treatment reduces delayed oligodendrocyte death, attenuates axonal dieback, and improves functional outcome after spinal cord injury. J Neurosci 24:2182-2190.

Tropepe V, Sibilia M, Ciruna BG, Rossant J, Wagner EF, van der Kooy D (1999) Distinct neural stem cells proliferate in response to EGF and FGF in the developing mouse telencephalon. Dev Biol 208:166-188.

Vescovi AL, Reynolds BA, Fraser DD, Weiss S (1993) bFGF regulates the proliferative fate of unipotent (neuronal) and bipotent (neuronal/astroglial) EGF-generated CNS progenitor cells. Neuron 11:951-966.

Vroemen M, Aigner L, Winkler J, Weidner N (2003) Adult neural progenitor cell grafts survive after acute spinal cord injury and integrate along axonal pathways. Eur J Neurosci 18:743-751. 
Wang X, Zhu S, Drozda M, Zhang W, Stavrovskaya IG, Cattaneo E, Ferrante RJ, Kristal BS, Friedlander RM (2003) Minocycline inhibits caspase-independent and -dependent mitochondrial cell death pathways in models of Huntington's disease. Proc Natl Acad Sci USA 100: 10483-10487.

Weiss S, Reynolds BA, Vescovi AL, Morshead C, Craig CG, van der Kooy D (1996a) Is there a neural stem cell in the mammalian forebrain? Trends Neurosci 19:387-393.

Weiss S, Dunne C, Hewson J, Wohl C, Wheatley M, Peterson AC, Reynolds BA (1996b) Multipotent CNS stem cells are present in the adult mammalian spinal cord and ventricular neuroaxis. J Neurosci 16: 7599-7609.
Yrjanheikki J, Keinanen R, Pellikka M, Hokfelt T, Koistinaho J (1998) Tetracyclines inhibit microglial activation and are neuroprotective in global brain ischemia. Proc Natl Acad Sci USA 95:15769-15774.

Yrjanheikki J, Tikka T, Keinanen R, Goldsteins G, Chan PH, Koistinaho J (1999) A tetracycline derivative, minocycline, reduces inflammation and protects against focal cerebral ischemia with a wide therapeutic window. Proc Natl Acad Sci USA 96:13496-13500.

Zhu S, Stravrovskaya IG, Drozda M, Kim BY, Ona V, Li M, Sarang S, Liu AS, Hartley DM, Wu du C, Gullans S, Ferrante RJ, Przedborski S, Kristal BS, Friedlander RM (2002) Minocycline inhibits cytochrome c release and delays progression of amyotrophic lateral sclerosis in mice. Nature 417: $74-78$. 